University of Louisville

ThinkIR: The University of Louisville's Institutional Repository

Electronic Theses and Dissertations

$7-2012$

\title{
Vehicle to grid as a household emergency generator for 2007 Toyota Prius plug-in hybrid electric vehicle.
}

Michael Schoen 1988-

University of Louisville

Follow this and additional works at: https://ir.library.louisville.edu/etd

\section{Recommended Citation}

Schoen, Michael 1988-, "Vehicle to grid as a household emergency generator for 2007 Toyota Prius plug-in hybrid electric vehicle." (2012). Electronic Theses and Dissertations. Paper 1278.

https://doi.org/10.18297/etd/1278

This Master's Thesis is brought to you for free and open access by ThinkIR: The University of Louisville's Institutional Repository. It has been accepted for inclusion in Electronic Theses and Dissertations by an authorized administrator of ThinkIR: The University of Louisville's Institutional Repository. This title appears here courtesy of the author, who has retained all other copyrights. For more information, please contact thinkir@louisville.edu. 


\title{
VEHICLE TO GRID AS A HOUSEHOLD EMERGENCY GENERATOR FOR 2007 TOYOTA PRIUS PLUG-IN HYBRID ELECTRIC VEHICLE
}

\author{
By \\ Michael Schoen \\ BS ECE, University of Louisville, 2012 \\ A Thesis \\ Submitted to the Faculty of the \\ J.B. Speed School of Engineering \\ in Partial fulfillment of the requirements \\ for the Degree of
}

Master of Engineering

Electrical and Computer Engineering Department

University of Louisville

Louisville, Kentucky

July 2012 


\title{
VEHICLE TO GRID AS A HOUSEHOLD EMERGENCY GENERATOR FOR 2007 TOYOTA PRIUS PLUG-IN HYBRID ELECTRIC VEHICLE
}

By

\author{
Michael Schoen \\ BS ECE, University of Louisville, 2012
}

A Thesis Approved on

August 26, 2011

By the following Thesis Committee:

Dr. Michael L. Mclntyre

Thesis Advisor

Dr. Lihui Bai

Dr. Karla Welch 


\section{DEDICATION}

This thesis is dedicated to my family, and especially to

Mr. Kevin Lynn Schoen

Mrs. Beverly Jo Schoen

Ms. Kristin Lynea Fields

Without the support and encouragement of them, I would never have been able to accomplish what I have. 


\section{ACKNOWLEDGEMENTS}

I would like to extend a very heartfelt thanks to Dr. Michael McIntyre for all of the guidance he has provided in this thesis. I always felt able to look to him for assistance and he has been an amazing instructor and mentor to me. I would also like to thank Dr. John Naber for his advice on my graduate studies and for helping me to find a topic of research that I find both interesting and enriching. In

addition, I would like to thank my family and friends who have been my support and drive throughout this endeavor. Without the support of those around me, I would never have been capable of this. 


\title{
ABSTRACT \\ VEHICLE TO GRID AS A HOUSEHOLD EMERGENCY GENERATOR FOR 2007 TOYOTA PRIUS PLUG-IN HYBRID ELECTRIC VEHICLE
}

\author{
Michael Kevin Schoen
}

July, 2012

Electric vehicles are quickly becoming one of the most rapidly growing technologies of this age. With their acceleration to prominence, the concept of Vehicle to Grid (V2G) becomes much more common as well. V2G is normally used as a supplement to the power grid to shave peak load levels, as a spinning reserve, or as a supplement to renewable energy sources. These vehicles can provide many advantages to consumers and power grid operators while also benefitting the environment. This paper explores an additional application where V2G could be of great benefit. This situation is the use of a V2G capable car to provide backup electricity generating capacity to an average American-style home (in terms of power consumption). This objective is completed in coordination with the IEEE 1547 Standard for Interconnecting Distributed Resources with Electric Power Systems. A 2007 Toyota Prius retrofitted to function as a Plug-In Hybrid Vehicle is used as a baseline. The output of the system is designated to be a single phase $240 \mathrm{~V}_{\mathrm{rms}} 60 \mathrm{~Hz}$ signal that would connect to the house grid. All steps in designing and simulating the interface are performed as well as selection of components including gate drive support systems. 


\section{TABLE OF CONTENTS}

PAGE

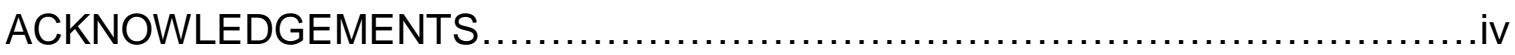

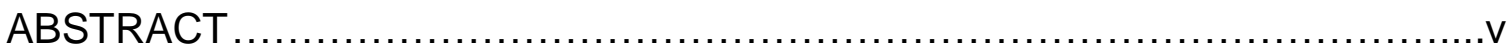

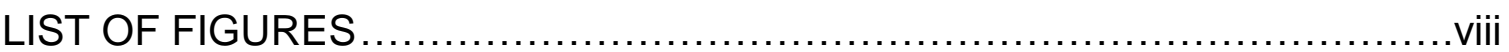

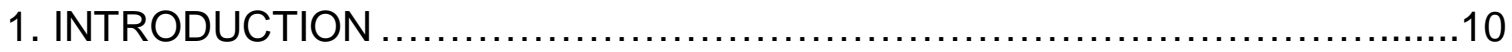

1.1 Types of Electric Vehicles ........................................... 10

1.2 Introduction to Vehicle to Grid ..................................... 13

1.3 Household Backup Generators ................................... 15

2. VEHICLE TO GRID INTERFACE FOR 2007 TOYOTA PRIUS PHEV ............17

2.1 Developing Design Specifications ...................................17

3. DESIGN OF VEHICLE TO GRID INTERFACE ..............................19

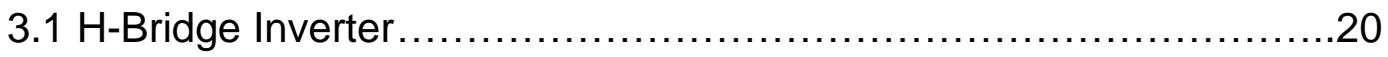

3.1.1 H-Bridge Inverter Design....................................24

3.1.2 H-Bridge Simulation.......................................26

3.1.3 Component Information .......................................

3.1.4 Power and Thermal Design ...................................31

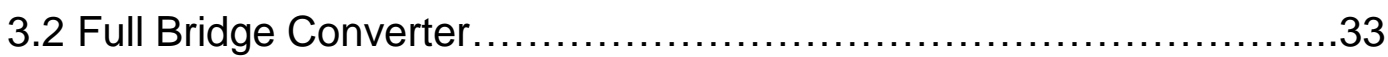

3.2.1 Full Bridge Converter Design..................................36

3.2.2 Full Bridge Converter Simulation.............................38

3.2.3 Component Information ....................................40

3.2.4 Power and Thermal Design.................................41

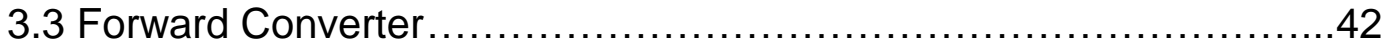

3.3.1 Forward Converter Design....................................47

3.3.2 Forward Converter Simulation.................................44

3.3.3 Component Information ....................................45 
3.3.4 Power and Thermal Design ................................47

3.4 Drive Support Systems ........................................... 48

3.4.1Gate Driver Circuit ..........................................49

3.4.2 Micro-Controller ............................................ 48

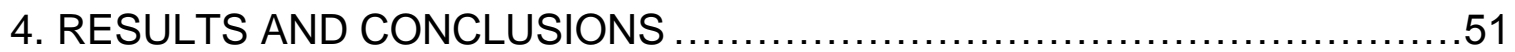

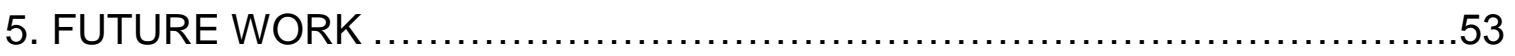

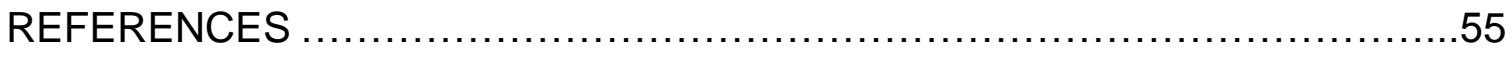

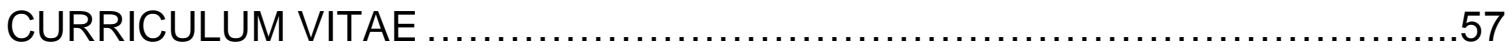




\section{LIST OF FIGURES}

FIGURE

PAGE

1.1 BEV Configuration ....................................................

1.2 HEV Configuration .................................................... 12

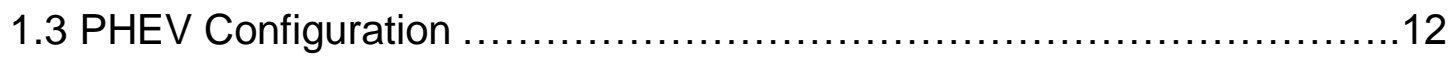

1.4 Effects of V2G Peak Shaving on Sardinia Island Test.....................13

1.5 Simulation of Dailey Power Grid Load Variations ...........................14

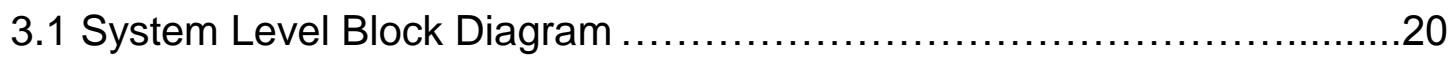

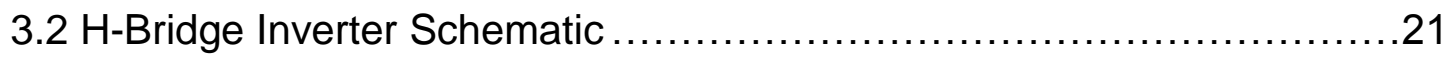

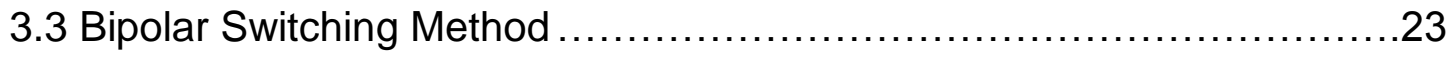

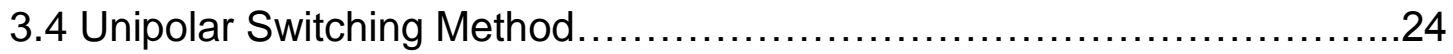

3.5 Normalized Fourier Coefficients for Bipolar PWM ........................26

3.6 Fourier Series Harmonic Analysis .........................................26

3.7 Simulation Schematic for H-Bridge Inverter ............................27

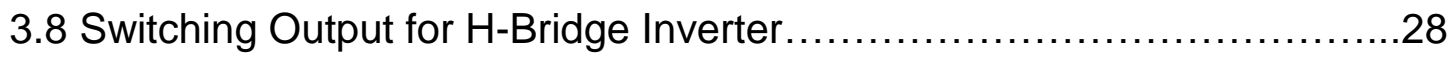

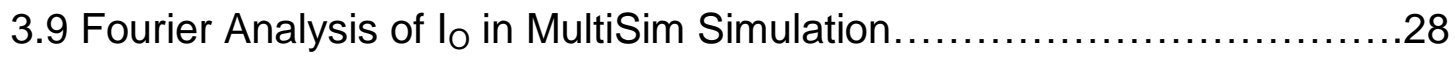

3.10 Fourier Analysis Zoomed on Additional Harmonics.......................29

3.11 Inverter IGBT Gate Voltage Transfer Characteristic ......................30

3.12 Power Dissipation Thermal Resistance Circuit...........................32

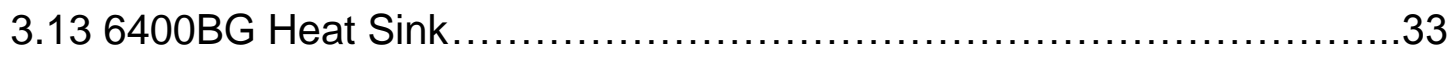

3.14 Full Bridge Converter Driving Signal....................................

3.15 Full Bridge Converter Schematic .........................................

3.16 Full Bridge Converter PLECSim Schematic ...............................38

3.17 Full Bridge Converter PLECSim Simulation Results......................39

3.18 Full Bridge Converter IGBT Gate Voltage Transfer Characteristic ........41

3.19 Forward Converter Schematic..........................................43

3.20 Forward Converter MultiSim Simulation ...............................45 
3.21 Forward Converter MOSFET Gate Voltage Transfer Characteristic......46

3.22 Aavid Thermalloy 530801B05150G Heat Sink.........................47

3.23 Location of Gate Drivers in Design ...................................48

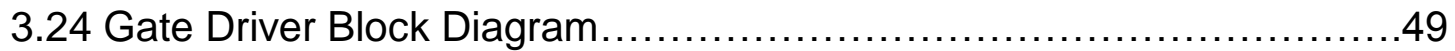

3.25 Location of Micro-Controller in Design ..................................50 


\section{CHAPTER 1}

\section{INTRODUCTION}

In recent years, electric vehicles (EV) have become much more popular to the average consumer. Cost of personal use EVs has gone down and, with gas prices on the rise and petroleum in high demand, the benefits of EV ownership have become much more apparent. EVs offer consumers high efficiencies, low noise, and reduced pollution over their internal combustion counterparts. This combination has been the chief focus of the EV's increase in popularity.

With the popularity of EVs brings introduction to a new technology, Vehicle to Grid (V2G). V2G is focused on the use of an EV connected to the power grid as a source for several different purposes. The focus of this thesis is the design of a V2G interface that would allow an EV plugged into a household to be used as a backup generator capable of powering common appliances and devices within. In this paper a brief introduction into EVs, V2G, and household backup generators is discussed. In addition, the design of a V2G interface for the specific objective of backup generating is planned, designed, and simulated completely.

\subsection{Types of Electric Vehicles}

EVs can be classified in several different ways, each with their own characteristics. The first is the Battery Electric Vehicle (BEV). The BEV is a vehicle that runs on power generated solely by its own battery pack which supplies power to its electric traction motor as shown in Figure 1.1. No gasoline 


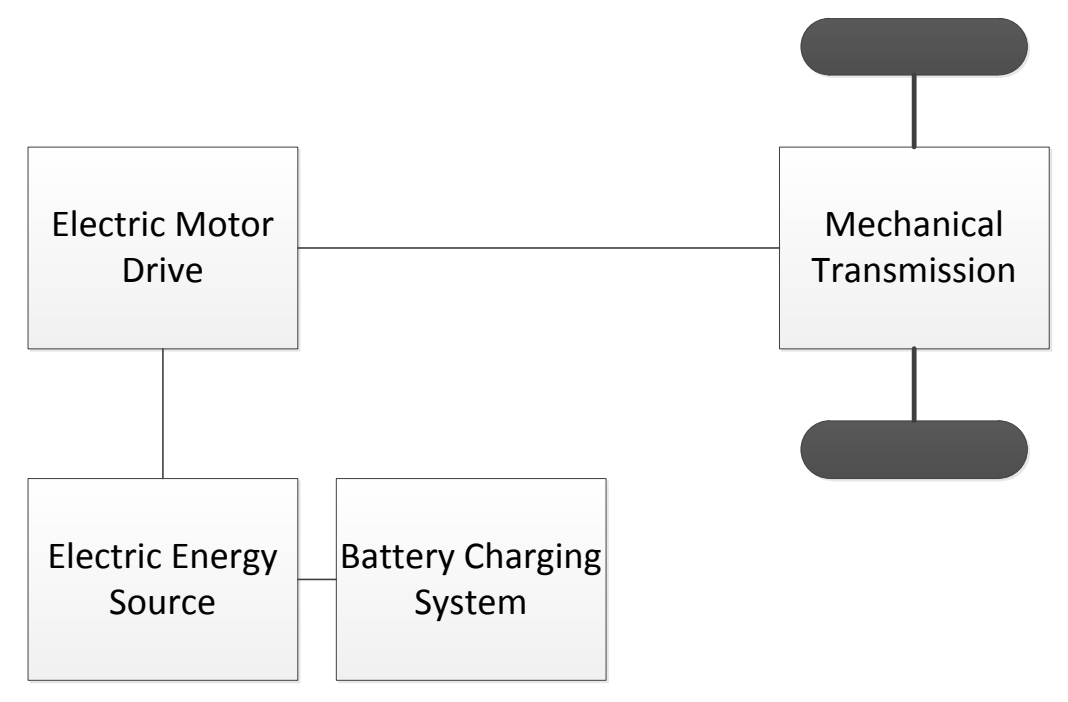

Figure 1.1: BEV Configuration [2]

is used in the operation of a BEV. Rather, any emissions associated with this type of vehicle are those caused by generating the electricity used to charge it. Still, this vehicle must recharge this battery pack much like an internal combustion vehicle must refuel regularly. The difference in that is with current battery charging technology, this recharge could take several hours to complete which many consumers may find unappealing. The second major type of EV is the Hybrid Electric Vehicle (HEV). This type of vehicle most closely resembles an internal combustion vehicle. As seen in Figure 1.2, the HEV uses an additional battery pack to store energy that would otherwise be wasted in an internal combustion engine such as using kinetic energy from braking to charge the additional battery. This stored energy can then be used when the car has need of it. This style of EV needs an internal combustion engine (ICE) to function, unlike the BEV, and also needs fuel to supply that engine. The third 
type of EV is the Plug-In Hybrid Electric Vehicle (PHEV). This type of vehicle is a mixture of the BEV and HEV as seen in Figure 1.3. It uses a large additional

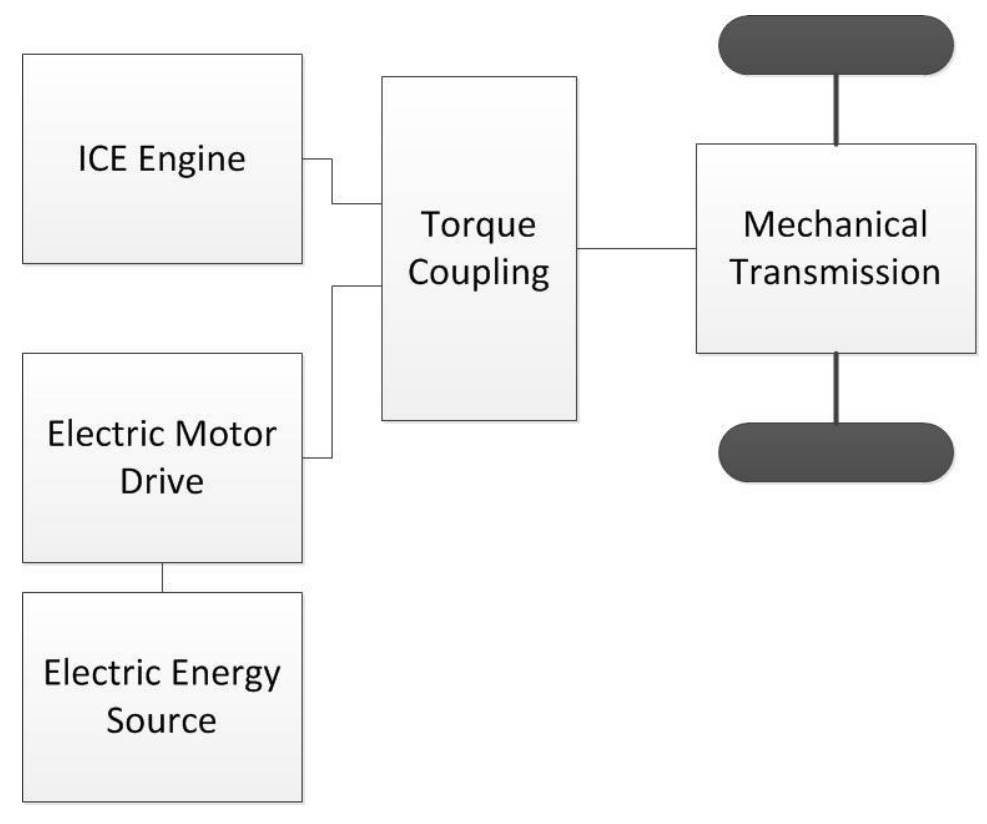

Figure 1.2: HEV Configuration [2]

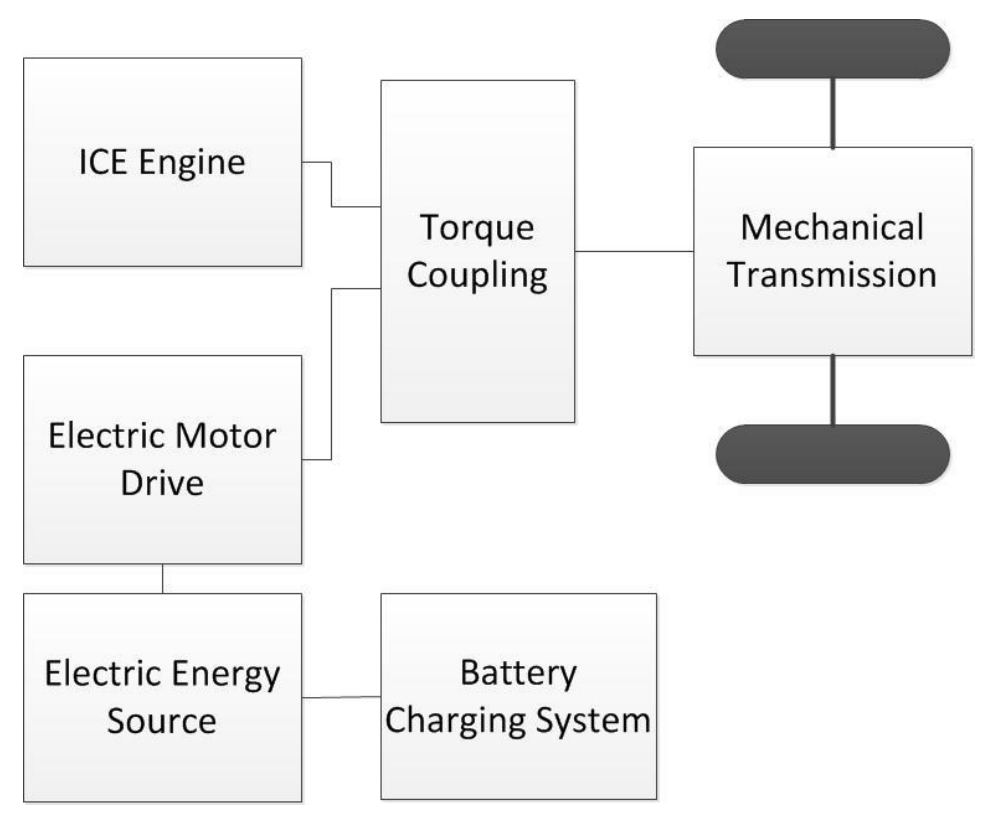

Figure 1.3: PHEV Configuration [2] 
battery like the HEV to supplement an ICE. The difference is that this pack can be charged from an external source similar to the BEV's battery. This makes the PHEV a good option for consumers who want the benefits of a BEV while not being completely reliant on the need for charging.

\subsection{Introduction of Vehicle to Grid}

With EV quickly becoming a sizeable population of the personal consumer vehicle fleet, another relatively new concept is becoming better known. This concept is called Vehicle to Grid. V2G refers to the functioning of a BEV or PHEV as a supplement to the power grid in some fashion. This functionality could take many different forms such as smoothing the load curve, improved reliability of power, or in a backup capacity [9].

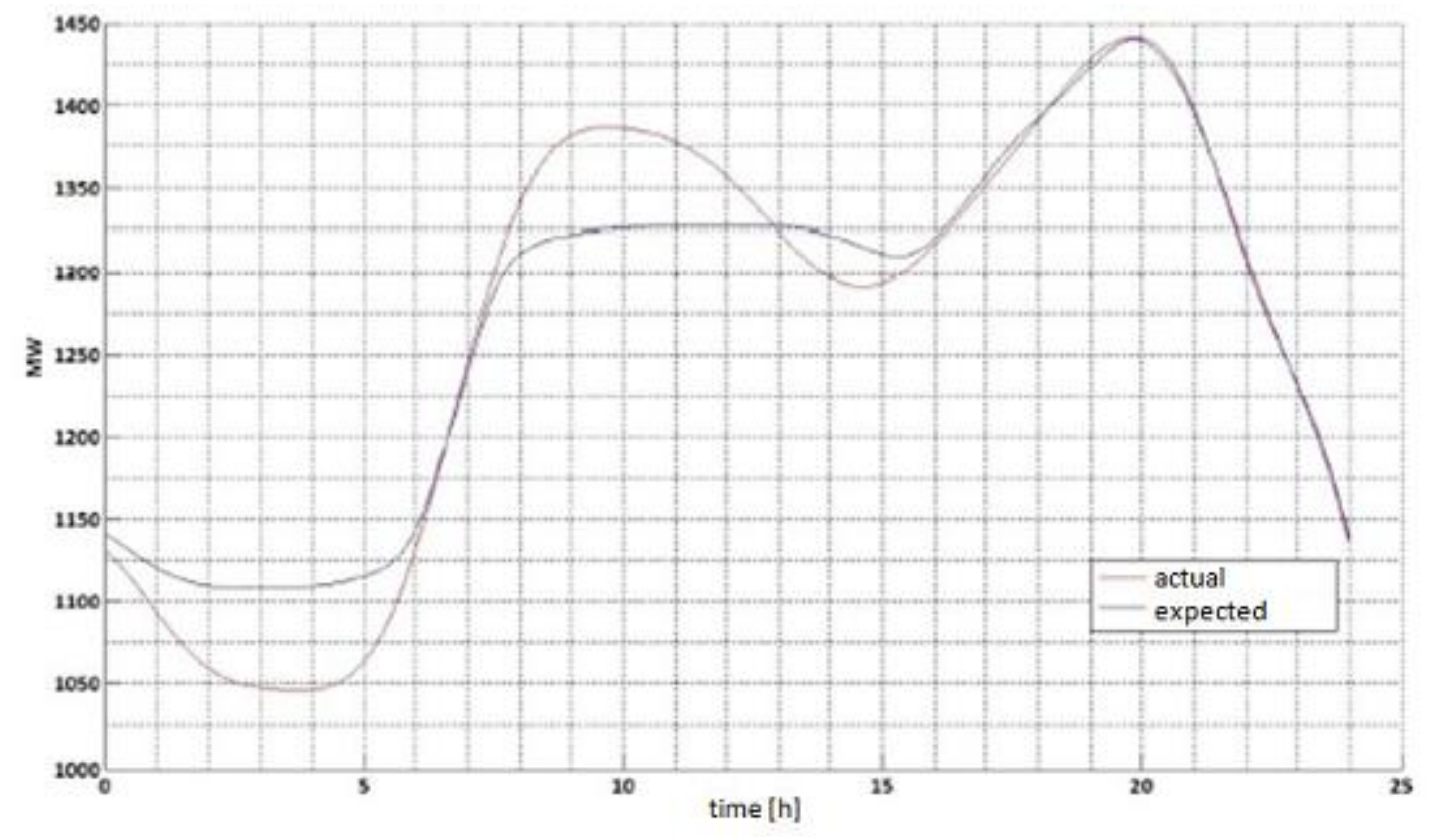

Figure 1.4: Effects of V2G Peak Shaving on Sardinia Island Test [1] 
A large fleet of BEVs and PHEVs can be of tremendous assistance for balancing the peak load that a power grid has during the day [8]. Normally, a power grid is at its greatest load from midday to evening, when most people are awake, the sun is shining, and appliances/devices are on as can be seen in Figure 1.5. Since this only occurs for a few hours a day, it is more economical to draw on a low cost source to supplement these needs instead of drawing that energy from a more expensive source like a power plant.

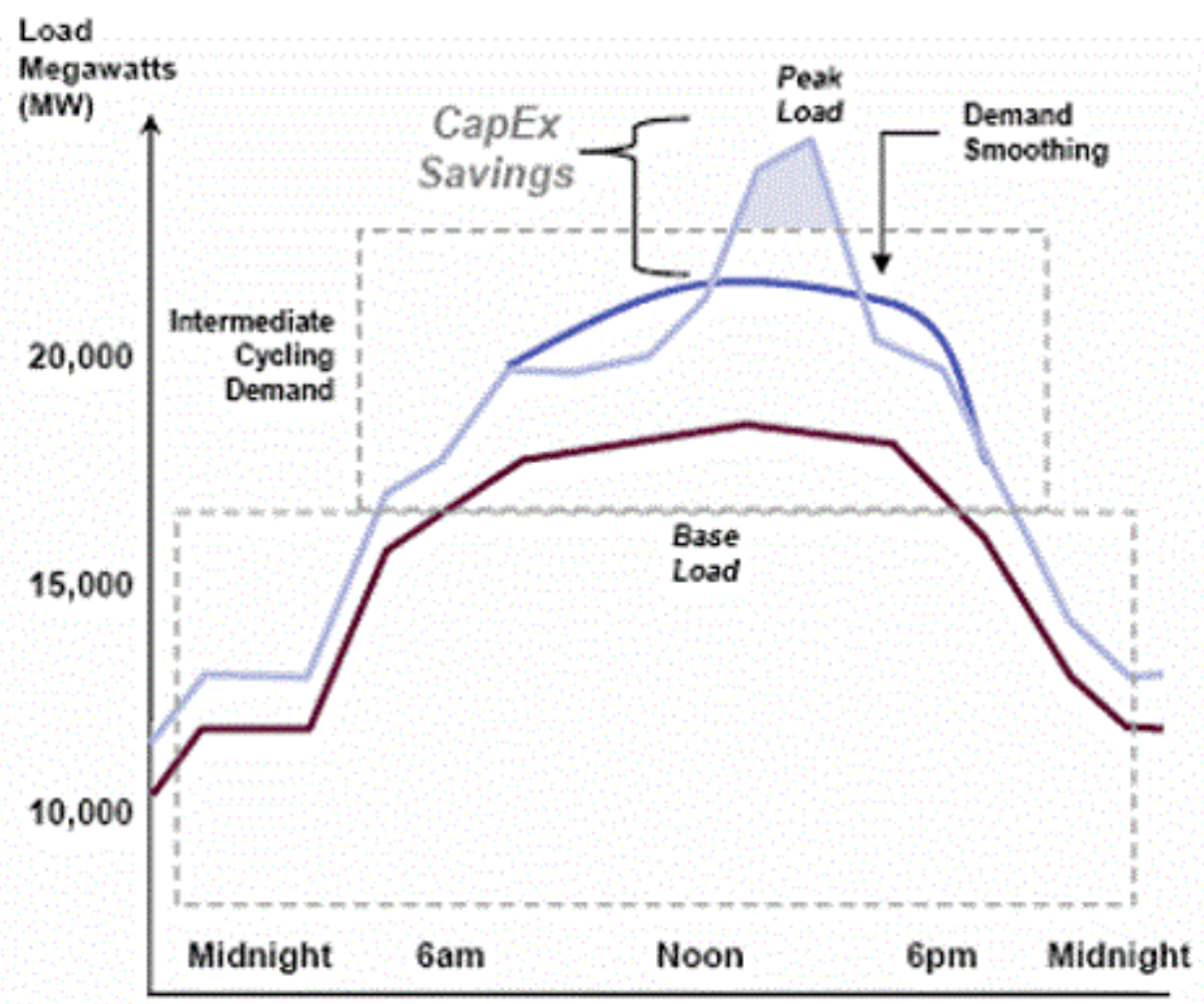

Figure 1.5: Simulation of Dailey Power Grid Load Variations [13]

EVs that are connected to the grid provide the opportunity for a consumer to "sell" energy stored in their battery to the electric company and to have the energy bought back at another time during the day when it is cheaper to produce 
and in less demand. In much the same style, V2G capable cars can provide a reserve of power in areas largely dependent on certain types of renewable energy. Generation sources such as wind and solar power are notorious for not being able to guarantee power when it is needed. Therefore, V2G capable vehicles can provide a reserve support system if it is needed [5] [6]. Energy can be drawn from these vehicles and then recharged at a later time when power is available from the grid. Finally, V2G capable vehicles are capable of providing a backup source of power for household use. In this instance, a V2G capable car can provide enough energy to power a household if the need arises, during a power outage for instance. A V2G interface can be used to keep the household running in much the same capacity a gasoline backup generator would. This is the specific situation that is the focus of this thesis.

Although using V2G to provide power to a single household has been listed as an option in several works [6] [9], at the time of publication the authors found no published work detailing the design necessary to achieve the energy transfer from an EV for use in a home setting. Therefore, this work is novel in its description of such a system and will serve as a comparison for any future designs in this research area.

\subsection{Household Backup Generators}

Since the focus of this work will be household backup generation, a logical first step is to look at current models of backup generators on the consumer market. Most backup generators for an average American house fall in the 5 to 
$20 \mathrm{~kW}$ range. For this thesis, the objective is to provide power to a house during a power outage and to allow close-to-normal operations for the occupants. Since this is a subjective stipulation, a baseline needs to be set. As far as this thesis is concerned, close-to-normal operation includes several more important appliances refrigerator, freezer, air conditioner (windowed or central), furnace fan, and water heater as well as a few amenities including approximately 10100 W light bulbs, television, computer system, dishwasher, electric clothes washer and dryer, and microwave oven. Using several generator sizing tools [10] [11], a generator size of 14 to $15 \mathrm{~kW}$ is recommended. The upper bound of $15 \mathrm{~kW}$ is chosen as the power objective for this research. A residential model generator of this capacity costs approximately $\$ 3,500$.

The final specification is the nature of the signal that will be supplied to the household. In the IEEE 1547 [4] electrical standard, electricity supplied from the power grid must meet a certain specification. For the scope of this thesis, a single phase line is selected. From the standard, single phase electricity must be a $240 \mathrm{~V} 60 \mathrm{~Hz}$ signal. In addition, this signal must be provided with less than $5 \%$ total harmonic distortion (THD). THD represents a measurement of the harmonic components compared to the fundamental frequency or how much the output deviates from the target output. Using different switching styles, the effects of additional harmonics can be lessened, as will be discussed in subsequent sections. With these objectives set, the design for this V2G interface is the next step. 


\section{CHAPTER 2}

\section{VEHICLE TO GRID INTERFACE FOR 2007 TOYOTA PRIUS PHEV}

This research work has the potential to give PHEV users an additional benefit to owning a V2G capable vehicle. Household backup generators provide a service that can be extremely useful but are not in constant need. Specifically, a V2G interface that can supply enough power to energize a normal American household has not been put into production and poses an interesting design objective. As a baseline for this thesis, a 2007 Toyota Prius PHEV retrofit will be used. However, this design is able to easily be adapted to other applications and vehicles.

\subsection{Developing Design Specifications}

The first step of this work is to determine some general specifications and assumptions. The 2007 Toyota Prius is retrofitted with a $240 \mathrm{~V}$ lead acid battery pack that has a rating of $400 \mathrm{~A}$-hrs in addition to its original battery pack and internal combustion engine (ICE). The output of the power electronic interface must meet the specifications set out in the IEEE 1547 standard for a $240 \mathrm{~V}_{\mathrm{ac}}, 60$ $\mathrm{Hz}$, single phase system with no more than 5\% THD. A common household backup generator that this proposed design would replace provides 10 to $20 \mathrm{~kW}$ of power. For the scope of this thesis, $15 \mathrm{~kW}$ was selected after some 
comparison to household backup generators [10] [11]. At $15 \mathrm{~kW}$, a consumer could expect to run several major appliances such as refrigerator/freezer, electric water heater, and central or wall air conditioner as well as several less significant amenities like a personal computer, television, dishwasher, etc. It is a common practice while designing a power electronic circuit to select a test load that would reflect the maximum power and draw from the battery pack. The load for this design is selected to be a series $3.84 \Omega$ resistance and a $20 \mathrm{mH}$ inductance. This resistance represents maximum power consumption while the inductance represents common inductance for motors used in air conditioning systems which is one of the larger inductive loads in most homes. By selecting this this power level for a V2G interface, it would allow a typical home owner to run major appliances and several amenities as mentioned previously. The retrofitted battery pack has the ability to drive this system for up to 11.2 hours based on the average current drawn of $35.82 \mathrm{~A}$ which is described in later sections, the battery rating of $400 \mathrm{~A}-\mathrm{hrs}$, and Equation 2.1.

$$
\text { Time }[\text { hours }]=\frac{\text { Battery } \text { Rating }}{\text { Average Current }}
$$




\section{CHAPTER 3}

\section{DESIGN OF VEHICLE TO GRID INTERFACE}

A series of Power Electronics Interfaces (PEI) were chosen to provide the $240 \mathrm{~V}_{\mathrm{rms}} 60 \mathrm{~Hz}$ single phase $\mathrm{AC}$ voltage waveform from the retrofitted Prius as seen in Figure 3.1. A PEI uses electronics for the control and conversion of electric power, matching the source to the load. This setup maintains the $5 \%$ THD, and provides a design that is reasonable to implement. Since the design uses separate interfaces feeding from one PEI to another, each block can be designed and tested separately to confirm individual functionality.

This work will start with the design of the $\mathrm{H}$-Bridge Inverter. This component performs the primary function of the design objectives, the conversion from direct current (DC) signal to alternating current $(A C)$ signal, and also sets requirements on other stages of the design. In a subsequent section, the Full Bridge converter is designed because it is directly connected to the $\mathrm{H}$ Bridge Inverter. The last designed stage is the Forward Converter which is used for low voltage DC requirements and support systems. In each of these sections, the steps behind designing each section are shown as well as the simulations and component selection information. In addition, the support systems such as 
the controller and gate drivers selected are discussed after the Forward Converter.

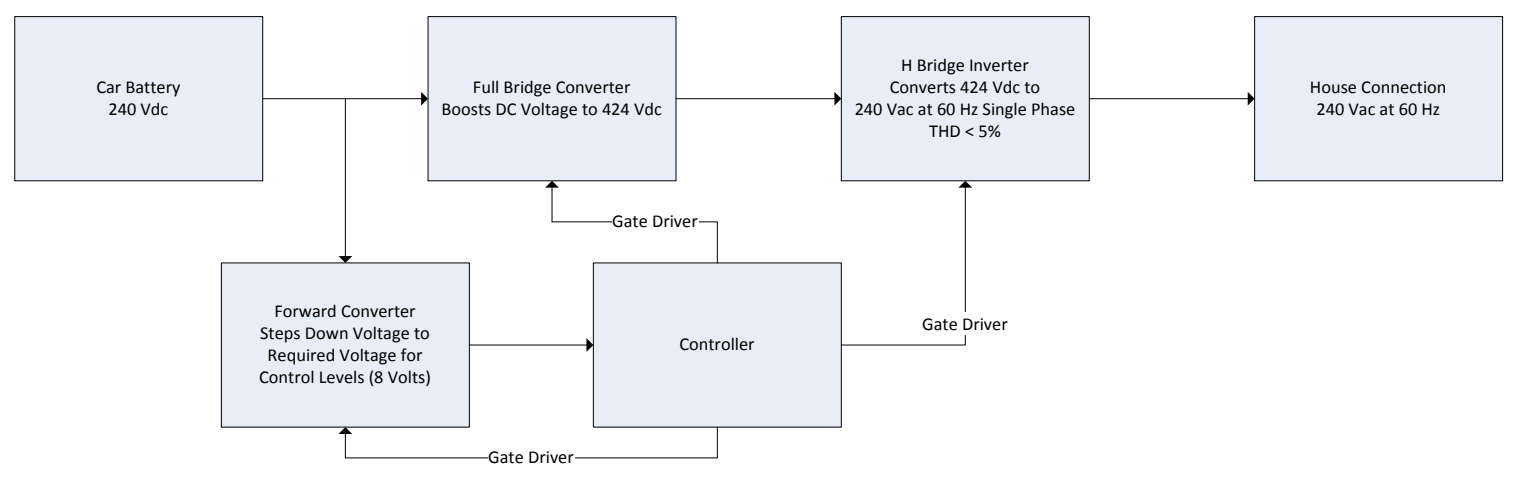

Figure 3.1: System Level Block Diagram

\subsection{H-Bridge Inverter}

An $\mathrm{H}$-Bridge Inverter is used to convert a DC voltage source into an AC voltage output, thus making it a key part of this design. Because the Prius' battery pack supplies a DC voltage, this stage is required for the output voltage waveform to be the AC signal required for use in a household electrical power system, which is $240 \mathrm{~V}_{\mathrm{rms}}, 60 \mathrm{~Hz}$, single phase. The end objective of this stage is to take the output from the Full Bridge Converter and use it to generate the $240 \mathrm{~V}$ AC signal at $60 \mathrm{~Hz}$ with a THD of less than $5 \%$ as required by IEEE 1547 . The $\mathrm{H}$-Bridge Inverter is created using 4 transistors, which are operated in either the cut-off region or the saturation region to provide a switching function [12]. These transistors are driven by a controller based on a pulse width modulated (PWM) signals. This PWM signals are generated using the comparison of a triangle wave signal $\left(\mathrm{V}_{\text {tri }}\right)$ and a sinusoidal signal $\left(\mathrm{V}_{\text {sine }}\right)$. These switches are arranged in 
the same fashion as those in Figure 3.2. The specifics of generating these two signals are discussed later in this section.

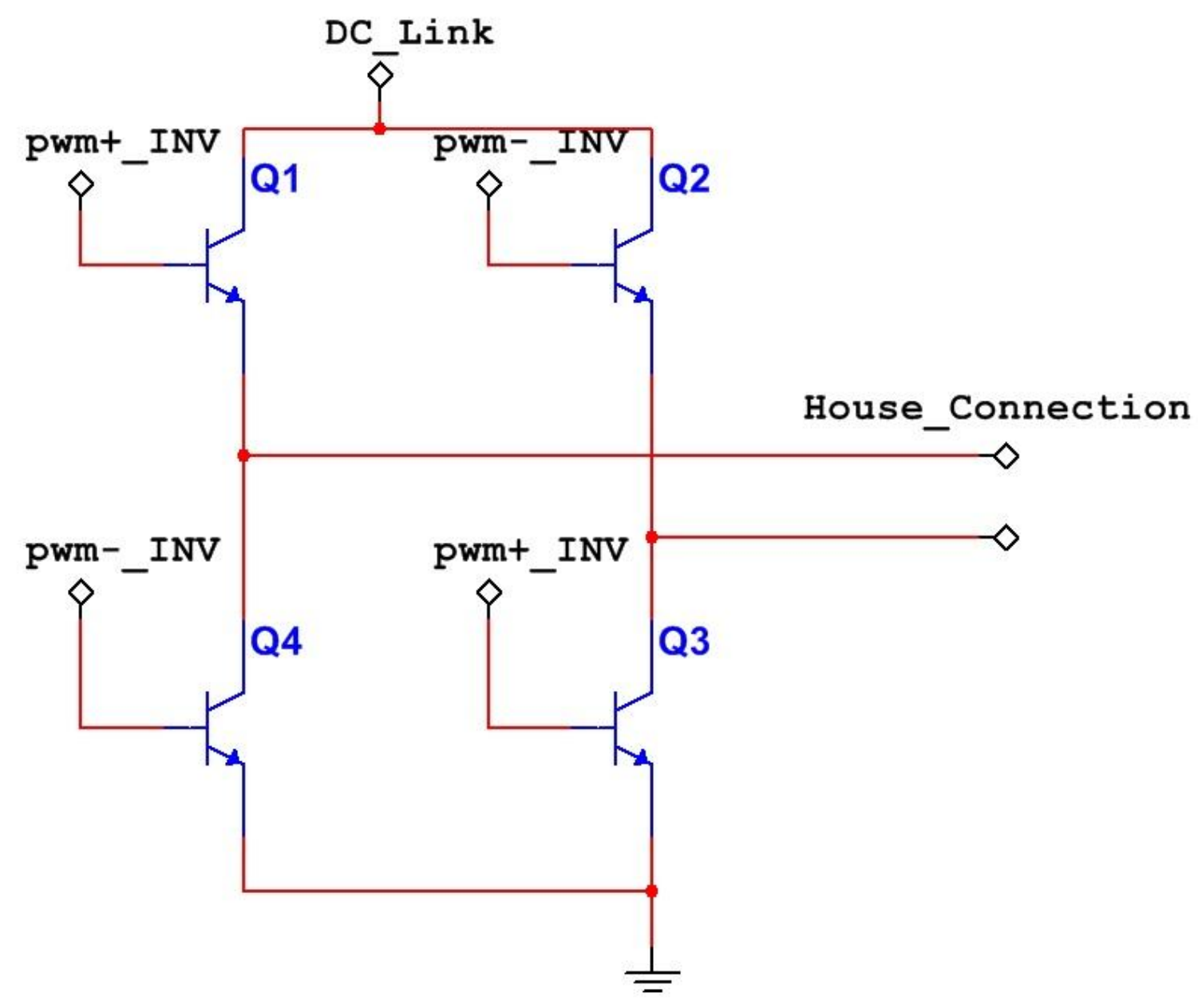

Figure 3.2: H-Bridge Inverter Schematic

For the scope of this thesis work, a bipolar switching algorithm, shown in Figure 3.3, is used for the PWM switching. Bipolar switching refers to the style of switching done by the transistors in the $\mathrm{H}$-Bridge setup, allowing the switches to only operate in pairs and not individually. This concept closes Q1 and Q3, setting the output voltage equal to the input voltage, when $V_{\text {sine }}$ is greater than $\mathrm{V}_{\text {tri. }}$ Conversely, Q2 and Q4 are closed, setting the output voltage equal to the 
negative of the input voltage, when $V_{\text {sine }}$ is less than $V_{\text {tri }}$ [3]. Neither set of switches can be on at the same time as its counterpart. Another important aspect of Bipolar Switching is the selection of the amplitude modulation $\left(\mathrm{m}_{\mathrm{a}}\right)$ and frequency modulation $\left(\mathrm{m}_{\mathrm{f}}\right)$ ratios. The amplitude modulation ratio is defined as the ratio between the amplitudes of the sinusoidal and triangle signals. It also represents the ratio between the input DC voltage and the amplitude of the output voltage at the fundamental frequency. The frequency modulation ratio is the ratio between the frequencies of the triangle and sinusoidal signals. Many PWM outputs have large harmonics generated but these harmonics can be placed far enough away from the fundamental frequency that a simple low pass filter can remove them [3]. The location of these harmonics are controlled by a multiple of the fundamental frequency, $60 \mathrm{~Hz}$ for this design. The modulation frequency ratio determines the multiple of the fundamental frequency that the large additional harmonics are placed. This is important because the further away from the fundamental frequency the harmonics are placed (the larger the frequency modulation ratio is) the lower the THD is for the system.

This switching method provides a voltage square wave as an output of either positive $V_{d c}$ or negative $V_{d c}$. This may not seem appropriate since the objective of this stage is to provide a sinusoidal output. However, due to the inductive load, the resulting current waveform will be a sinusoid. By modifying the amplitude and frequency modulation ratios involved in the generation of the voltage square wave, the characteristics of the current sinusoid can be controlled 
to meet the desired output. All of this together results in an output similar to that shown in Figure 3.3.

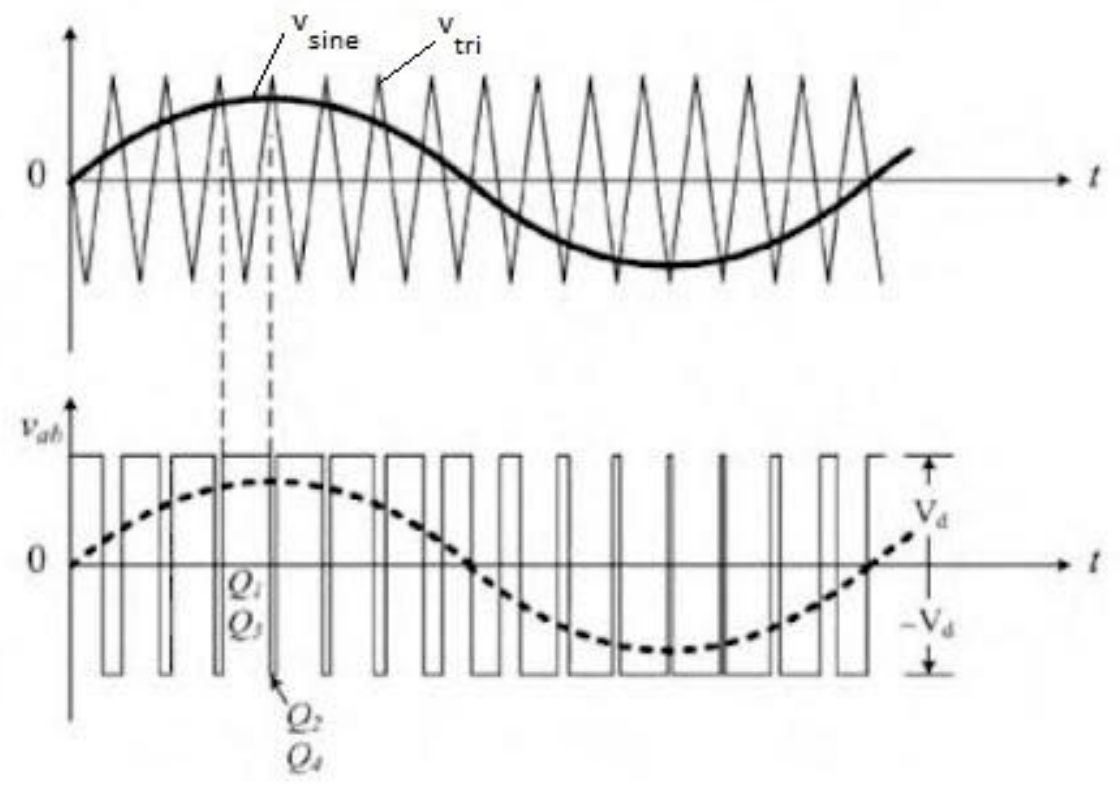

Figure 3.3: Bipolar Switching Method [3]

In addition to the bipolar switching algorithm, there are other methods that can provide the correct switching signals for an $\mathrm{H}$ bridge inverter. There is unipolar switching, where the output can be switched from high to zero or from low to zero instead of just between high and low as in bipolar switching as shown in Figure 3.4. Also, harmonics in unipolar switching are generated at twice the frequency from where bipolar algorithms typically do [3]. There is also space vector modulation, which is commonly used in 3 phase inverter designs. The bipolar switching method works best in this design due to the small amount of generated harmonics in this system. 


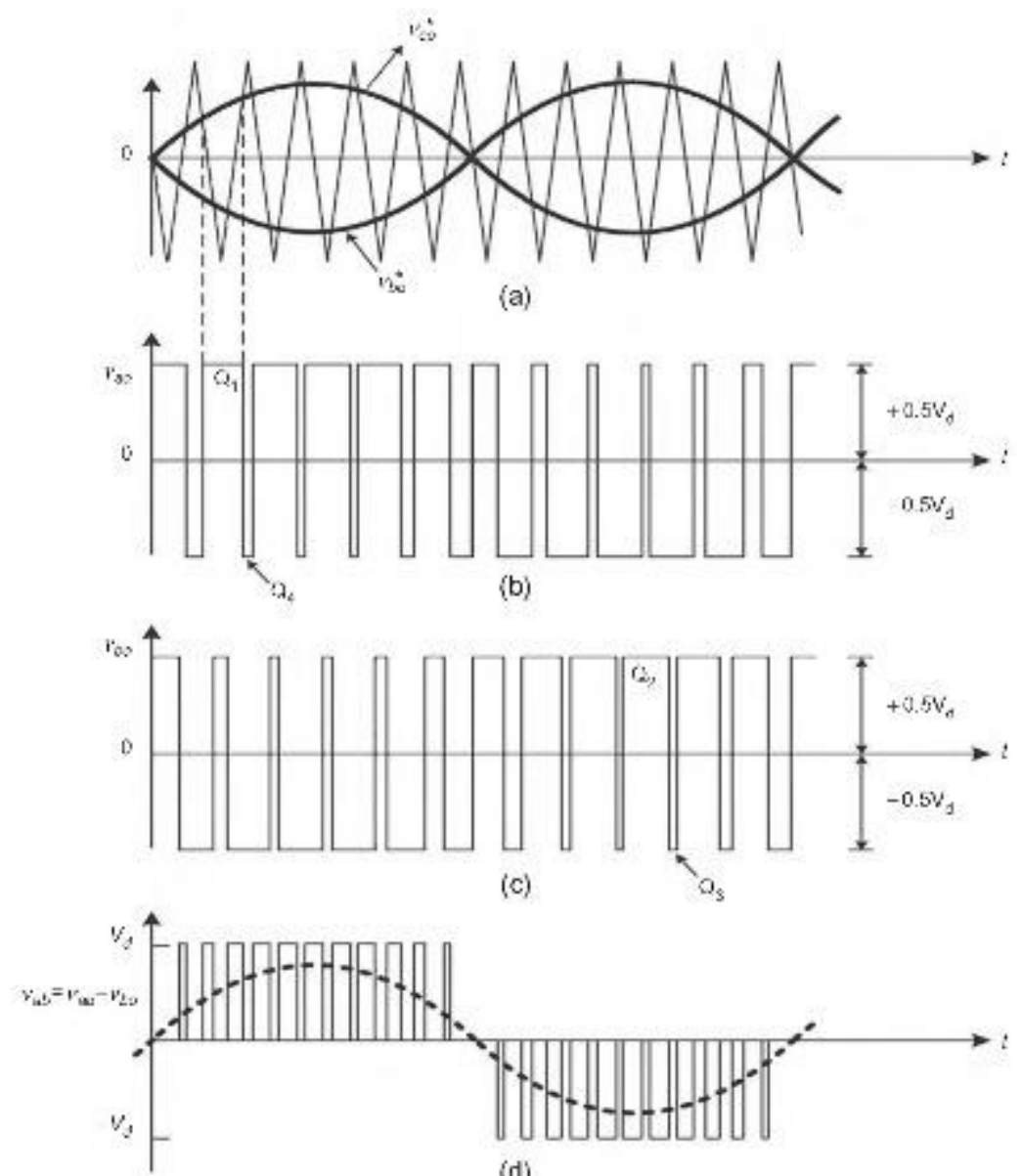

(d)

Figure 3.4: Unipolar Switching Method [3]

\subsubsection{H-Bridge Inverter Design}

After selecting the circuit topology and PWM switching methods, next is to design the interface. For the circuit design of this PEI stage as well as the other two stages, equations and design steps are performed using Power Electronics by Daniel Hart as a reference [3]. For the design work on the H-Bridge Inverter, the first step is to look at the output voltage needed. Since the output is required to be $240 \mathrm{~V}_{\mathrm{rms}}$, the peak is found to be $339.41 \mathrm{~V}_{\mathrm{dc}}$ using Equation 3.1. Next, the 


$$
V_{p}=240 \times \sqrt{2}=339.41 \mathrm{~V}
$$

modulation amplitude ratio $\left(\mathrm{m}_{\mathrm{a}}\right)$ is chosen. This ratio controls the $\mathrm{V}_{\text {peak }}$ of the fundamental frequency with respect to the input voltage and is selected to be 0.8 so the input voltage is kept as low as possible while still allowing some room for adjustment. This ratio is typically selected be between 0 and 1 in order to keep a linear relationship between the input voltage and the fundamental frequency voltage. Using this value, the required input voltage can be determined at 424.26 $\mathrm{V}$ using Equation 3.2. For the purposes of this design, the input voltage is rounded to $424 \mathrm{~V}$ and that is the value used for the DC Link bus. The next step

$$
\mathrm{V}_{1}=\frac{V_{O}}{m_{a}}=424.26 \mathrm{~V}
$$

in design is to select the frequency modulation ratio $\left(m_{\mathrm{f}}\right)$ which will determine where large additional harmonics occur. The minimum value is determined using Equation 3.3 and is then increased, moving them further from the fundamental

$$
m_{f}>\frac{Z_{m f}}{2 \times \pi \times f \times L}
$$

frequency, until the required THD of $5 \%$ is met. The ratio is selected for this is design to be 27 which corresponds to harmonics being located at $1620 \mathrm{~Hz}$. The coefficients for determining voltages are given in Figure 3.5. These voltages represent the peak values at each harmonic and can be used with Ohm's Law to determine a value for current to be used to calculate THD with Equation 3.4. The results for these calculations are shown in Figure 3.6. THD for this design is kept at $3.64 \%$, which is well within the requirements set out at the beginning of the 
research project. The values determined for input voltage, $m_{a}$, and $m_{f}$ allow the design to be implemented and the input voltage sets the requirements for the DC Link bus along with the next stage of the work.

$$
T H D_{1}=\frac{\sqrt{\sum_{n}^{\infty} I_{n, r m s}^{2}}}{I_{1, r m s}}
$$

\begin{tabular}{ccccccccccc}
\hline & $\mathbf{m}_{\mathbf{a}}=\mathbf{1}$ & $\mathbf{0 . 9}$ & $\mathbf{0 . 8}$ & $\mathbf{0 . 7}$ & $\mathbf{0 . 6}$ & $\mathbf{0 . 5}$ & $\mathbf{0 . 4}$ & $\mathbf{0 . 3}$ & $\mathbf{0 . 2}$ & $\mathbf{0 . 1}$ \\
\hline $\mathrm{n}=1$ & 1.00 & 0.90 & 0.80 & 0.70 & 0.60 & 0.50 & 0.40 & 0.30 & 0.20 & 0.10 \\
$\mathrm{n}=\mathrm{m}_{\mathrm{f}}$ & 0.60 & 0.71 & 0.82 & 0.92 & 1.01 & 1.08 & 1.15 & 1.20 & 1.24 & 1.27 \\
$\mathrm{n}=\mathrm{m}_{\mathrm{f}} \pm 2$ & 0.32 & 0.27 & 0.22 & 0.17 & 0.13 & 0.09 & 0.06 & 0.03 & 0.02 & 0.00 \\
\hline
\end{tabular}

Figure 3.5: Normalized Fourier Coefficients for Bipolar PWM [3]

\begin{tabular}{|l|r|r|r|r|}
\hline Targeted Harmonic & 27 & & & \\
\hline THD & $3.64 \%$ & & & \\
\hline & & & & \\
\hline Harmonic & Frequency & Voltage & Impedance & Current \\
\hline 1 & 60 & 339.20 & 8.44 & 40.17 \\
\hline 25 & 1500 & 74.62 & 188.53 & 0.40 \\
\hline 27 & 1620 & 278.14 & 203.61 & 1.37 \\
\hline 29 & 1740 & 74.62 & 218.69 & 0.34 \\
\hline
\end{tabular}

Figure 3.6: Fourier Series Harmonic Analysis

\subsubsection{H-Bridge Simulation Results}

All simulations for this stage are done using National Instrument's MultiSim software package. Creating a $\pm 424 \mathrm{~V}$ signal is difficult in MultiSim with transistors or switches, so a comparator is used to perform the same function. 
This simulation has 2 sources as inputs to the comparator that generate the pulse width modulated signal and allows a Fourier analysis to be performed on the system. The peak voltage for the $V_{\text {sine }}$ source was chosen based on the modulation amplitude ratio of the inverter with a frequency that is the same as the desired output of $60 \mathrm{~Hz}$. The $\mathrm{V}_{\text {tri }}$ source is set to switch between -1 and $1 \mathrm{~V}$ at a period of $.61728 \mathrm{msec}$ which is the inverse of $1620 \mathrm{~Hz}$. This comparator is set to have an output of $\pm 424 \mathrm{~V}$ based on the input voltage from the DC Link Bus. $\mathrm{R} 1$ and L1 are chosen based on the desired test load for this design. With this setup, a Bipolar Switching Algorithm is achieved as set out in the previous section.

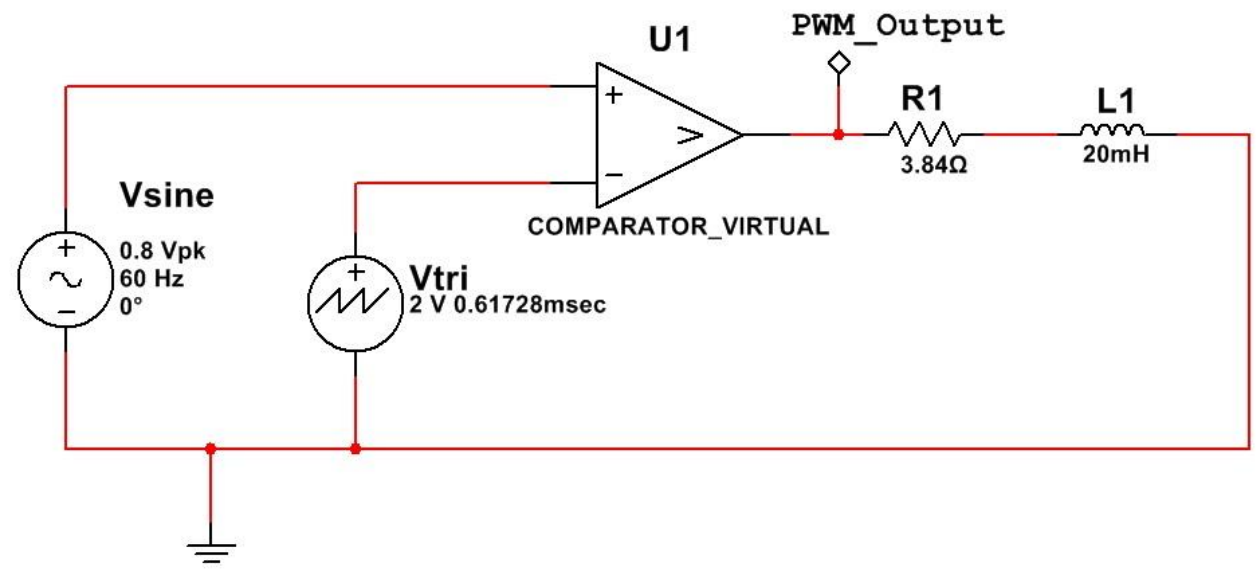

Figure 3.7: Simulation Schematic for H-Bridge Inverter 


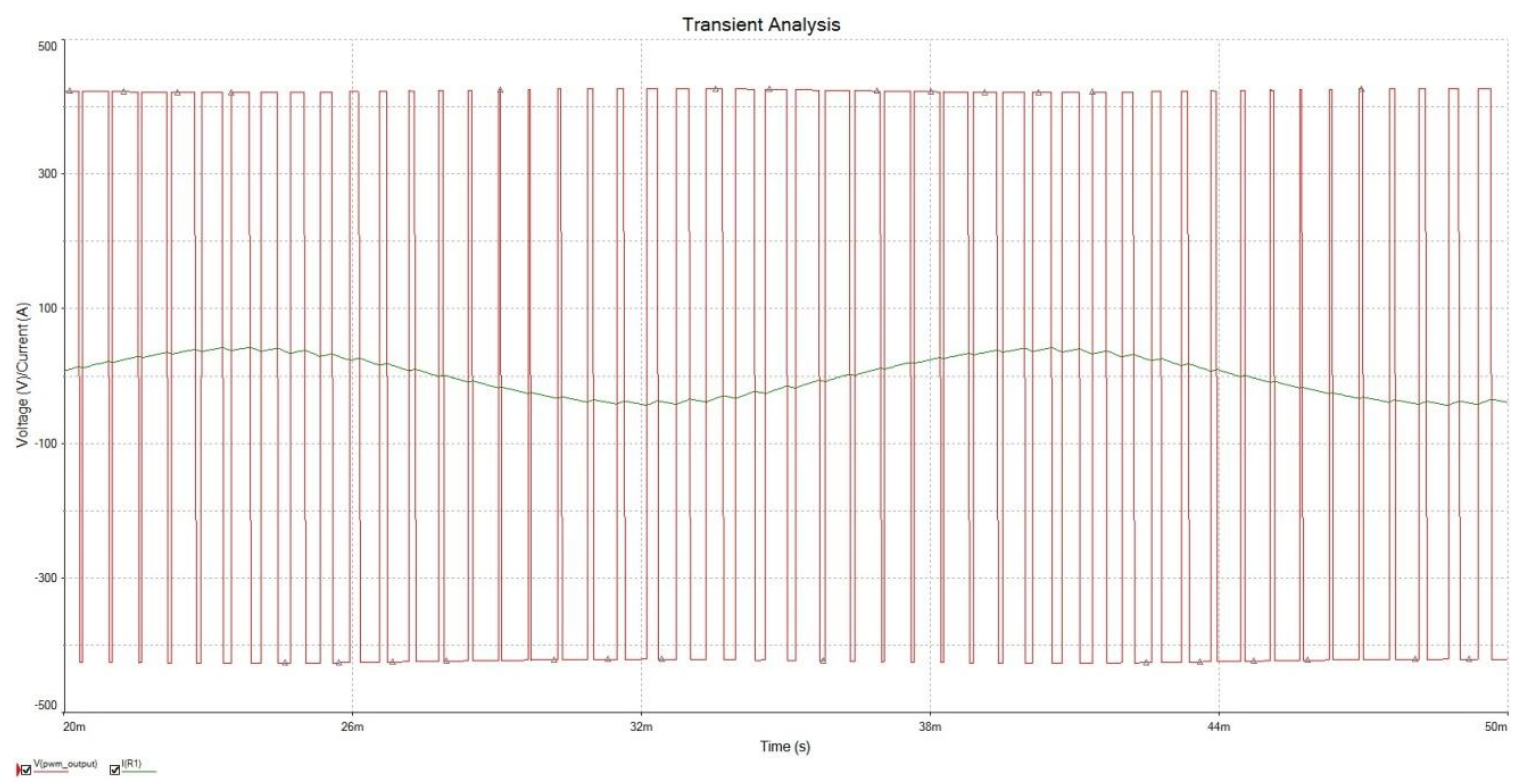

Figure 3.8: Switching Output for H-Bridge Inverter (Voltage and Current)

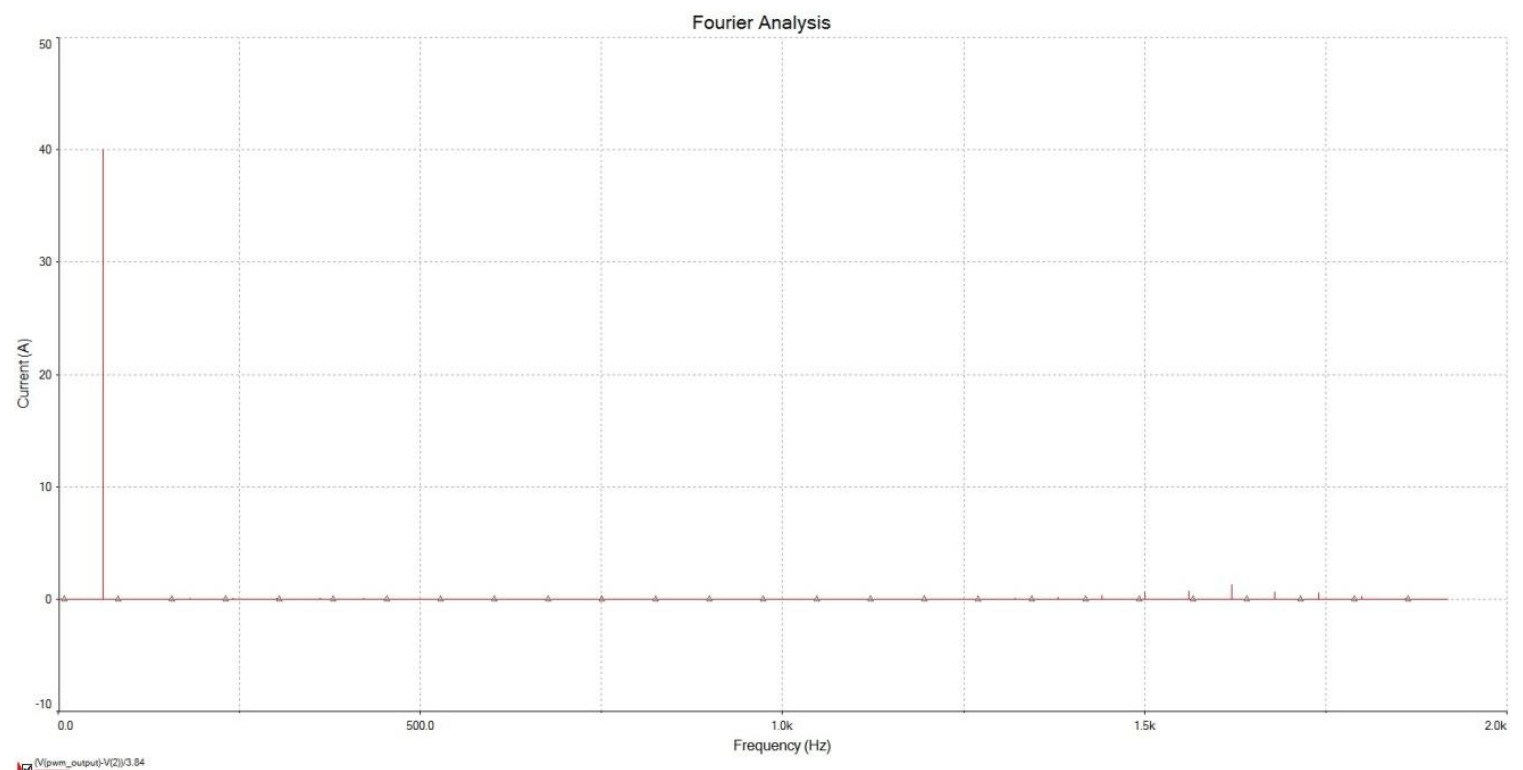

Figure 3.9: Fourier Analysis of $\mathrm{I}_{\mathrm{O}}(\mathrm{t})$ in MultiSim Simulation 


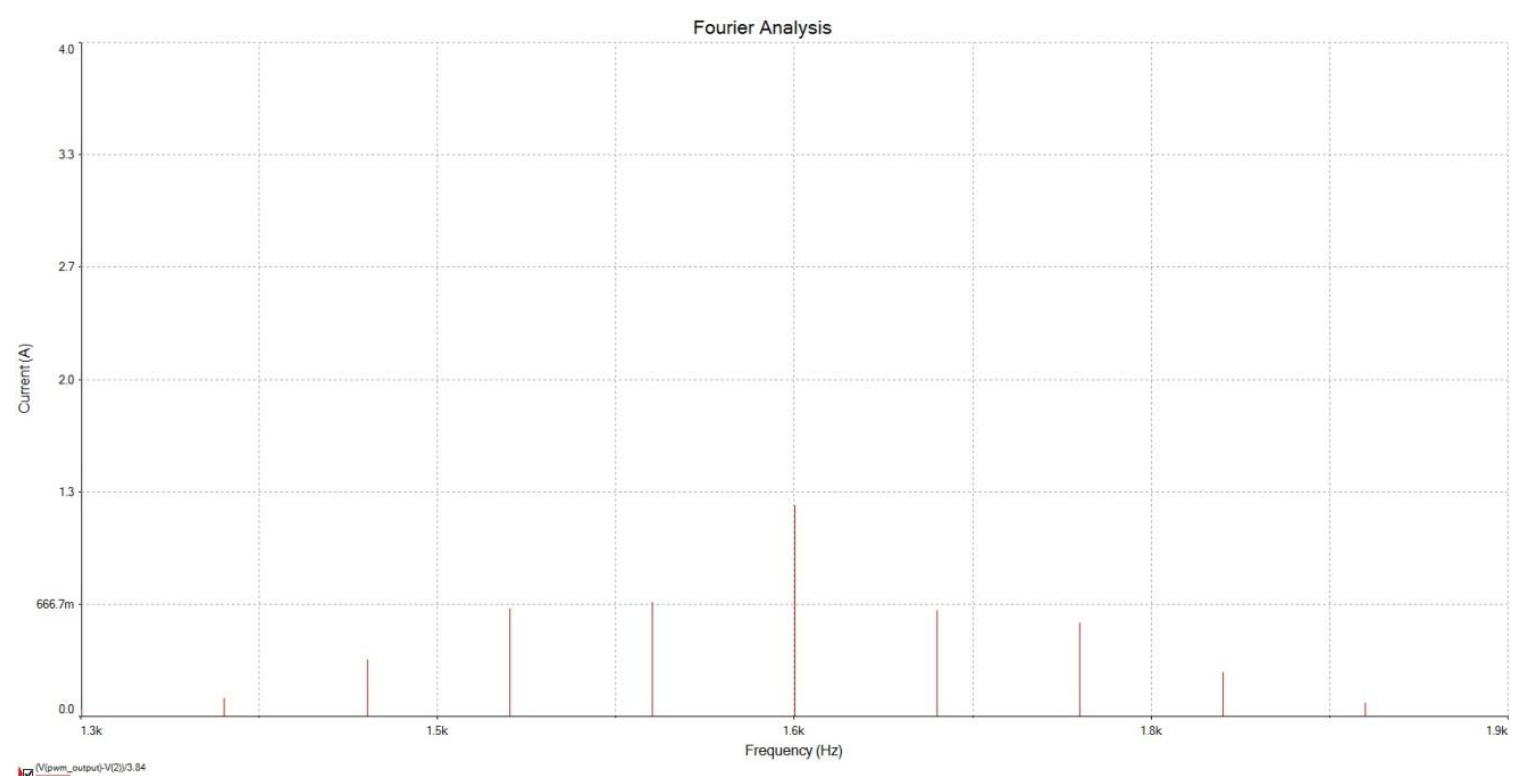

Figure 3.10: Fourier Analysis Zoomed on Additional Harmonics

As the simulation in Figure 3.8 shows, the transient output of this system results in a voltage that switches back and forth between $\pm 424 \mathrm{~V}$ in a similar fashion to the example bipolar output shown in Figure 3.3. Figure 3.9 shows the overall magnitudes of current at various frequencies and that all aberrant harmonics appear near $1620 \mathrm{~Hz}$ just as was intended by design, which are shown zoomed in on Figure 3.10. These harmonics are extremely small by comparison to the fundamental frequency current value of 40.17 A from the Fourier analysis shown in Figure 3.6.

\subsubsection{Component Selection}

For this stage, there are several devices that can be used for the switches. This stage requires a blocking voltage of at least $424 \mathrm{~V}_{\mathrm{dc}}$, a passing current of 40.17 A, and be able to switch at $1620 \mathrm{~Hz}$. IGBTs are selected over other types 
of transistors because they have lower power losses at the low frequencies this stage operates. They also keep conduction losses smaller than other options. The specific part chosen is the International Rectifier IRG4PC50FD. This transistor has a blocking voltage of $600 \mathrm{~V}$ with a maximum pulse current allowance of $280 \mathrm{~A}$, both within operating conditions for this stage. This transistor has a collector-to-emitter voltage $\left(\mathrm{V}_{\mathrm{CE}(\mathrm{on})}\right)$ of $1.45 \mathrm{~V}$. It also has a combined turn on time $\left(\mathrm{t}_{\text {con }}\right)$ of 86 nsec and a combined turn off time $\left(\mathrm{t}_{\text {coff }}\right)$ of 660 nsec. These values are very important for calculating losses for this component. This model needs to be driven by a gate voltage of about $6.5 \mathrm{~V}$ based on the information in Figure 3.11, to be supplied by the gate driver of this stage. Once component selection is complete, the next step is to perform a thermal and power loss analysis.

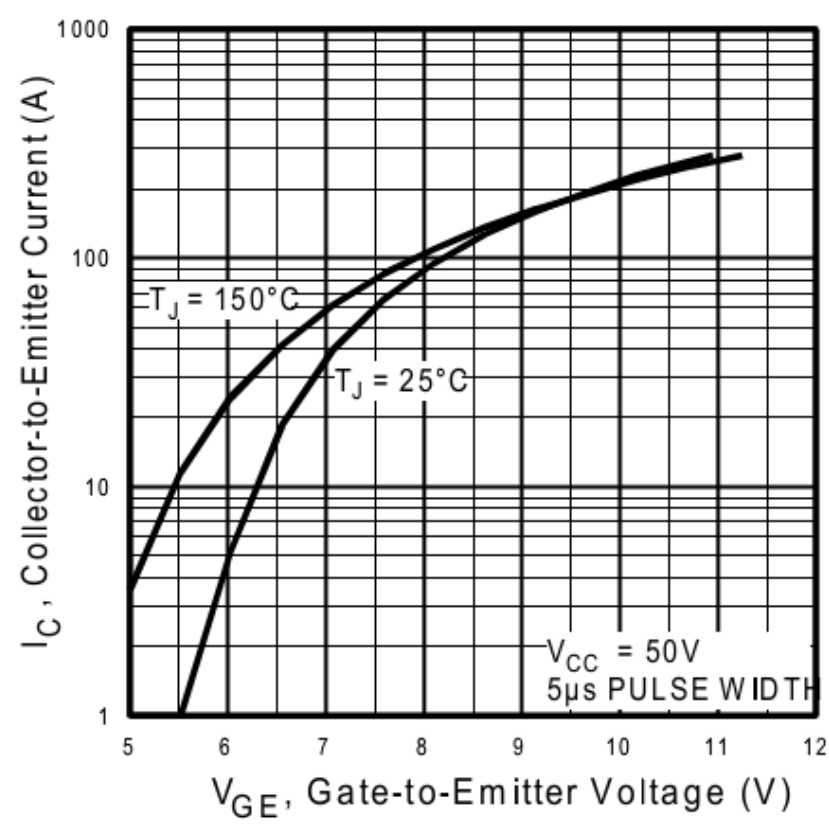

Figure 3.11: Inverter IGBT Gate Voltage Transfer Characteristic 


\subsubsection{Power and Thermal Analysis}

Power is lost in this stage due to the switches in both conduction and during turn on and turn off switching. For this analysis, power losses are calculated when the duty cycle (D) is at its maximum, due to the variance in duty cycle associated with driving this stage. For a PWM signal, the switching cycles vary between $0 \%$ and $80 \%$ at the switching frequency. This means that the same amount of switching occurs each cycle, regardless of the duty cycle. However, this maximum duty cycle represents the worst case for conduction losses since this is when the IGBT will be conducting for the longest percentage of the cycle. This case is found at $1620 \mathrm{~Hz}$ to be approximately $89.48 \%$. Using this value, conduction losses are calculated to be $36.86 \mathrm{~W}$ using Equation 3.5, where $I_{\text {Drms }}$ equals $28.41 \mathrm{~A}$ from the output current of this stage. On the other hand, switching losses are at $8.23 \mathrm{~W}$ using Equation 3.6. Summing these values together gives combined losses for the inverter stage at $45.09 \mathrm{~W}$. Using a one

$$
\begin{gathered}
P_{C}=D V_{C E(\text { on })} I_{D r m s} \\
P_{S W}=.5 V_{1} I_{1}\left(t_{c o n}+t_{c o f f}\right) f
\end{gathered}
$$

dimensional thermal analysis equivalent circuit like that in Figure 3.12 where $P$ is the total power lost, one obtains Equation 3.7 [7]. The selected IGBT has a junction-to-case thermal resistance $\left(R_{\theta, J C}\right)$ of $0.64^{\circ} \mathrm{C} / W$. The Sil-Free thermal grease that interfaces between the IGBT and heat sink has a case-to-sink thermal resistance $\left(R_{\theta, C S}\right)$ of $0.24{ }^{\circ} \mathrm{C} / W$. Using these values and the combined 
power loss of $45.09 \mathrm{~W}$, this design requires a $R_{\theta, S A}$ of $1.56{ }^{\circ} \mathrm{C} / \mathrm{W}$. This value is too low given the current available types of heat sinks. Therefore, as an alternate solution, two IGBTs in parallel are used instead of single IGBT for each switch effectively halving the current through each transistor and the power

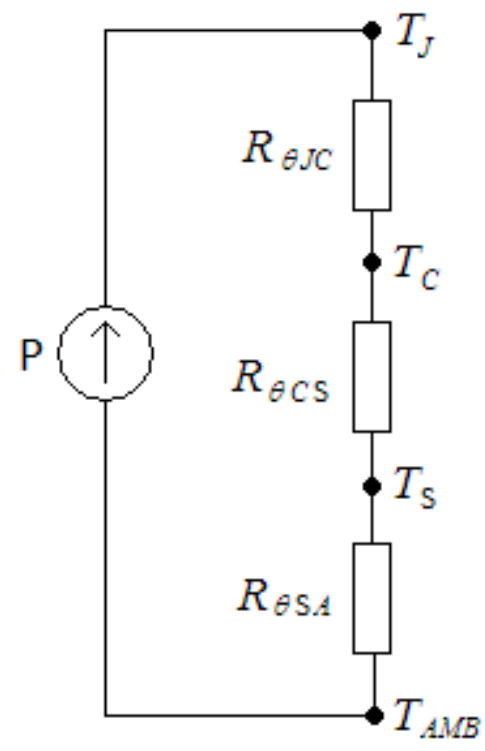

Figure 3.12: Power Dissipation Thermal Resistance Circuit [7]

dissipated across them. This combination allows the power loss to be lowered to a more manageable level. With this modification and Equation 3.7, a thermal resistance for the heat sink is determined to be $R_{\theta, S A}$ of $3.99^{\circ} \mathrm{C} / W$ at $150^{\circ} \mathrm{C}$. The

$$
P=\frac{T_{j}-T_{a}}{R_{\theta, J C}+R_{\theta, C S}+R_{\theta, S A}}
$$


6400BG heat sink from Aavid Thermalloy, shown in Figure 3.13, provides $R_{\theta, S A}$ of $2.7^{\circ} \mathrm{C} / \mathrm{W}$ and will match the IR IGBT transistors used. Together this will provide a junction temperature of $124^{\circ} \mathrm{C}$ which is an optimal temperature to operate the IGBTs.

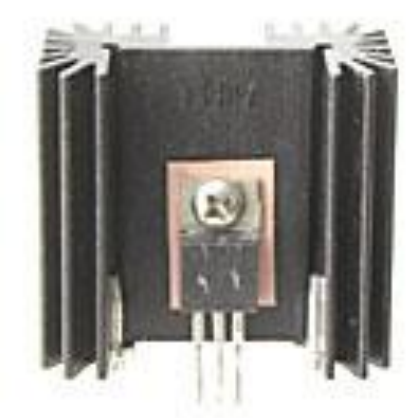

Figure 3.13: 6400BG Heat Sink

The $\mathrm{H}$-Bridge Inverter forms one of the major pieces of this thesis work. This section takes a specific DC voltage and provides the $240 \mathrm{~V}_{\mathrm{rms}} 60 \mathrm{~Hz}$ single phase signal set out as an objective of the design. In order to provide this signal, an appropriate input DC voltage of $424 \mathrm{~V}$ is needed. In the subsequent section, a Full Bridge converter will adjust the $240 \mathrm{Vdc}$ delivered from the batteries to the required $424 \mathrm{Vdc}$.

\subsection{Full Bridge Converter}

With the design of the H-Bridge Inverter as it stands, a larger DC voltage is required than what the Prius' battery can readily provide. As such, an interface to provide that larger DC voltage is needed to maintain the $15 \mathrm{~kW}$ power objective. For this stage, a Full Bridge Converter is selected. The Full 
Bridge Converter uses a combination of an $\mathrm{H}$ bridge of transistors, similar to the $\mathrm{H}$ bridge inverter from the previous section [3]. This array is operated by two equal square waves driven at the designed frequency and duty cycle with one square wave offset from the other by half of the switching time (inverse of the switching frequency) as is shown in Figure 3.14. The bridge is isolated from a
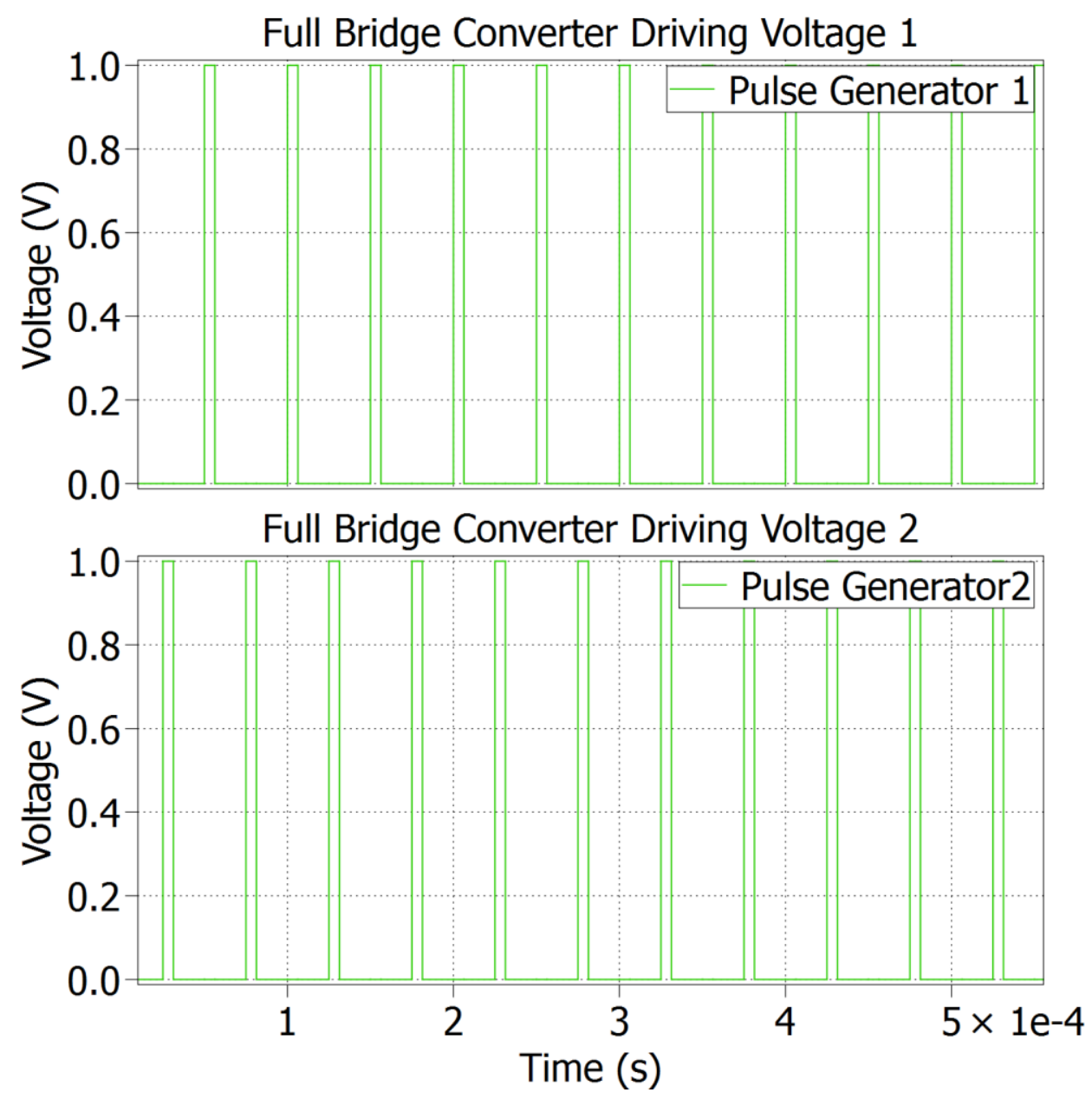

Figure 3.14: Full Bridge Converter Driving Signal

buck converter by a center tapped transformer as shown in Figure 3.15. This stage needs to provide the $424 \mathrm{~V}$ required by the inverter stage using the 240 Vdc input from the Prius with a small amount of variance (to prevent generating 
additional harmonics). Output voltage ripple is selected to be within $1 \%$ while current ripple is to be kept so that the converter always operates in the continuous conduction mode, meaning the current stored in the inductor fluctuates but never reaches zero. It is general practice for power electronics dealing with larger load currents to operate in the continuous current mode. A transformer works well in this situation because of the large increase in voltage. This design uses the turns ratio in the transformer to adjust the voltage level. Also, this design allows for a smaller switching frequency $(<100 \mathrm{k} \mathrm{kHz})$ to be used, both lowering the minimum inductance and the inductor current variance. A non-transformer design would need a high switching frequency (> $300 \mathrm{kHz})$ to have a manageable inductor size and to keep inductor current greater than zero. The high switching frequency required would result in very high switching losses. For the design objectives, a switching frequency of $20 \mathrm{kHz}$ is selected. This value is suitably low to keep switching losses from dominating the thermal analysis while still allowing for the minimum inductance to maintain continuous current operation to be kept relatively low. 


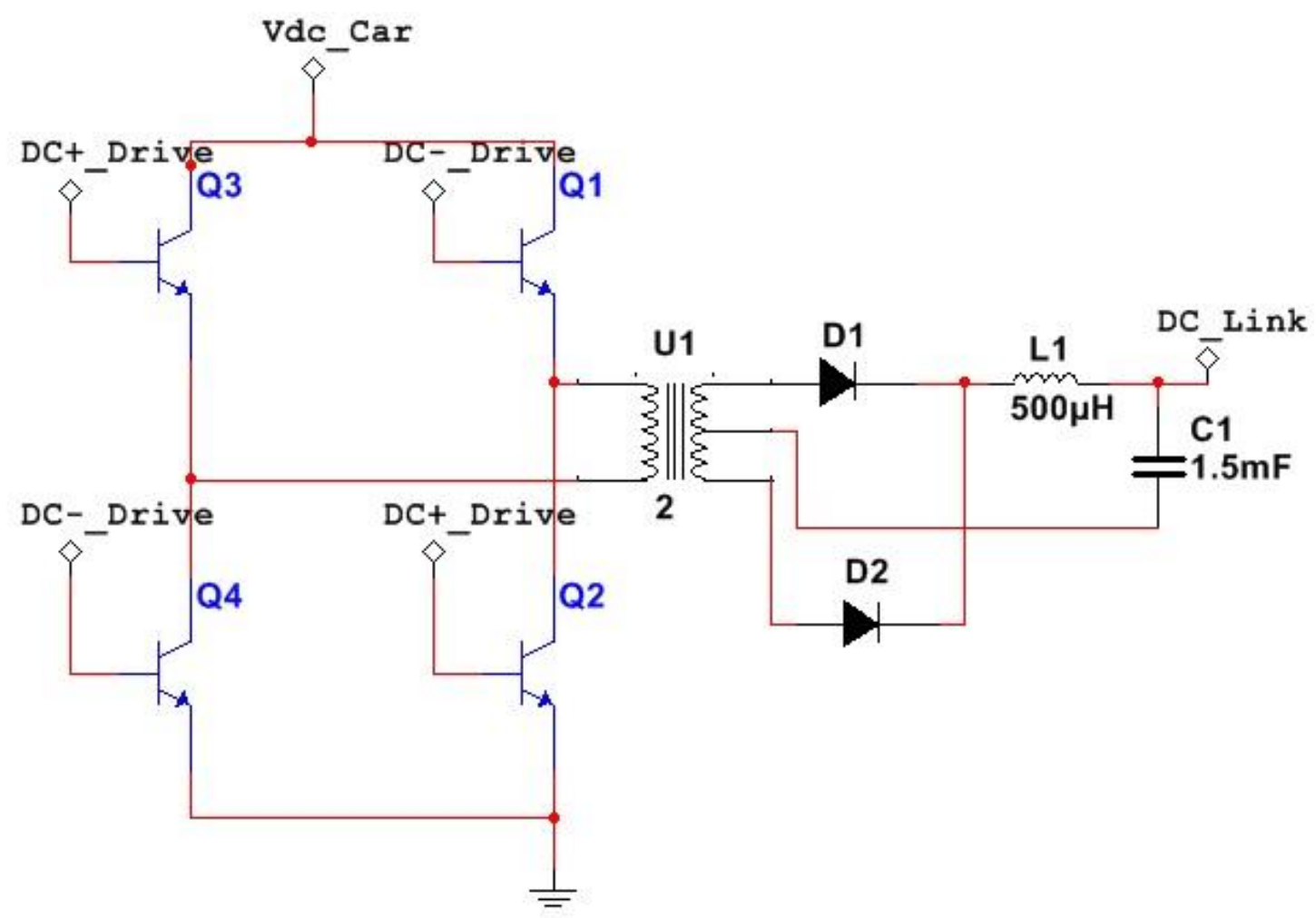

Figure 3.15: Full Bridge Converter Schematic

\subsubsection{Full Bridge Converter Design}

Once the specifications of the stage have been set, the next objective is to begin designing the converter. For the design of the Full Bridge Converter, the first step is to look at the relationship between input and output voltages. Since the inverter requires an input of $424 \mathrm{~V}$, this is selected as the DC Link bus voltage which is the output of this stage. In addition, the transformer is chosen to have a turns ratio between the primary and secondary winding $(\mathrm{N})$ to be 7 . This is used to step up the input value to a larger value while the duty cycle will decrease back to desired output. Using these, a source voltage $\left(V_{s}\right)$ of $240 \mathrm{~V}$ from the Prius, and Equation 3.8 duty cycle is determined to be $25.23 \%$. 


$$
D=\frac{V_{O}}{V_{S} N}
$$

Average output current is found using Equation 3.9 to be $35.82 \mathrm{~A}$ using the load resistance $(R)$ of $12 \Omega$ chosen using the desired output power of $15 \mathrm{~kW}$ and this stage's output, $424 \mathrm{~V}$. The switching frequency (f) is the $20 \mathrm{kHz}$ decided on in the specifications for this stage. The minimum inductor value for continuous current operation is chosen with Equation 3.10 and can be increased as needed

$$
\begin{gathered}
I_{L}=\frac{V_{S}}{R(1-D)^{2}} \\
L_{\text {min }}=\frac{D(1-D)^{2} R}{2 f}
\end{gathered}
$$

to provide a suitably low ripple in the output current. For this design, the minimum inductor value is calculated to be $42 \mathrm{uH}$ but is raised to $500 \mathrm{uH}$ to reduce the ripple current down to a minimum. The output ripple current is found by determining how much the output current varies, halving it, and comparing it to the average output current from Equation 3.9. The change in output current is determined by Equation 3.11 to be $6.06 \mathrm{~A}$, leaving the maximum current at

$$
\Delta I_{L}=\frac{V_{s} D}{L f}
$$

41.88 $\mathrm{A}$ and the minimum at 29.77 A. Finally, the minimum capacitance value is found using the specified output voltage ripple $\left(\frac{d V_{o}}{V_{o}}\right)$ of $1 \%$ and Equation 3.12 to be $1.05 \mathrm{mF}$. Pulling all these values together is the basis for designing the Full Bridge Converter. 


$$
C_{\min }=\frac{D}{f \times \frac{d V_{O}}{V_{O}} \times R}
$$

\subsubsection{Full Bridge Converter Simulation Result}

Simulations for the Full Bridge Converter are performed using PLECSim Standalone version. This software package allows for the $\mathrm{H}$-Bridge of transistors to be simulated as an array of switches driven by equal pulse generator sources with the second generator offset by half of the switching frequency. Figure 3.16 shows the schematic used to simulate this design while Figure 3.17 is the resulting simulation. All values are set to the values specified in the previous section with $\mathrm{V} \_d c$ corresponding to the source voltage and the voltmeter reading the output voltage to the DC Link bus. $R_{\text {load }}$ is the test resistance for this stage, selected to be $12 \Omega$ reflecting a $15 \mathrm{~kW}$ draw on this device.

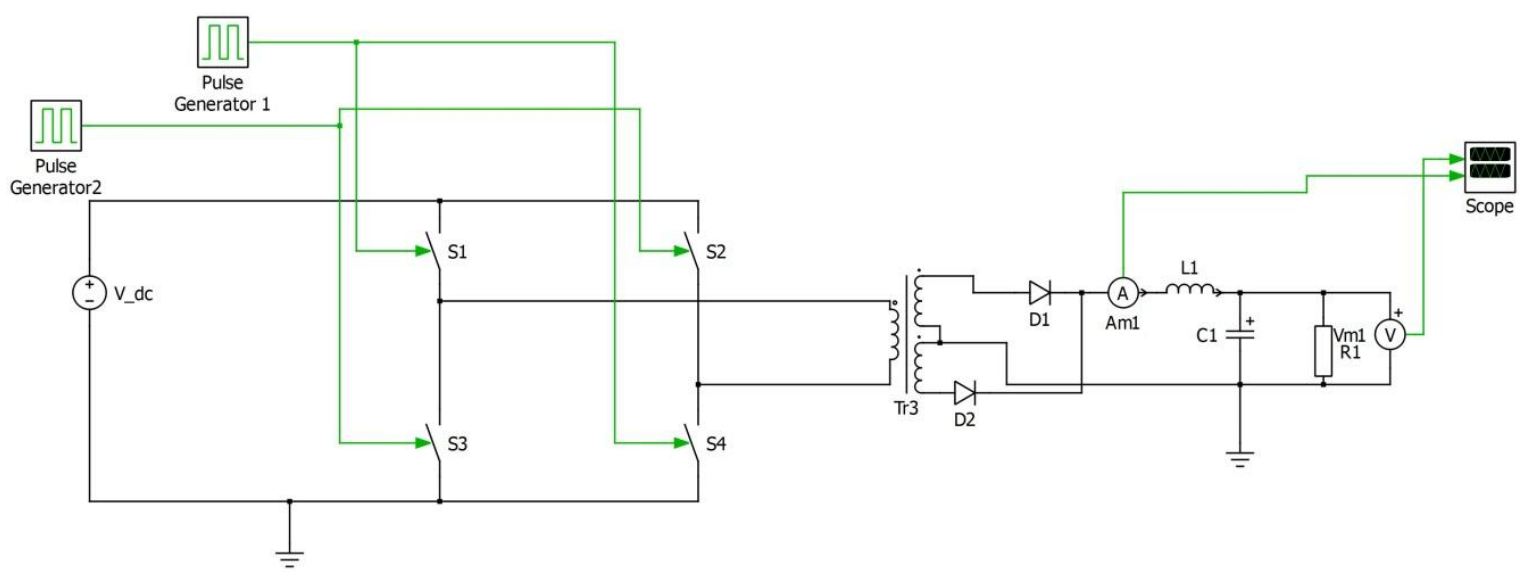

Figure 3.16: Full Bridge Converter PLECSim Schematic 

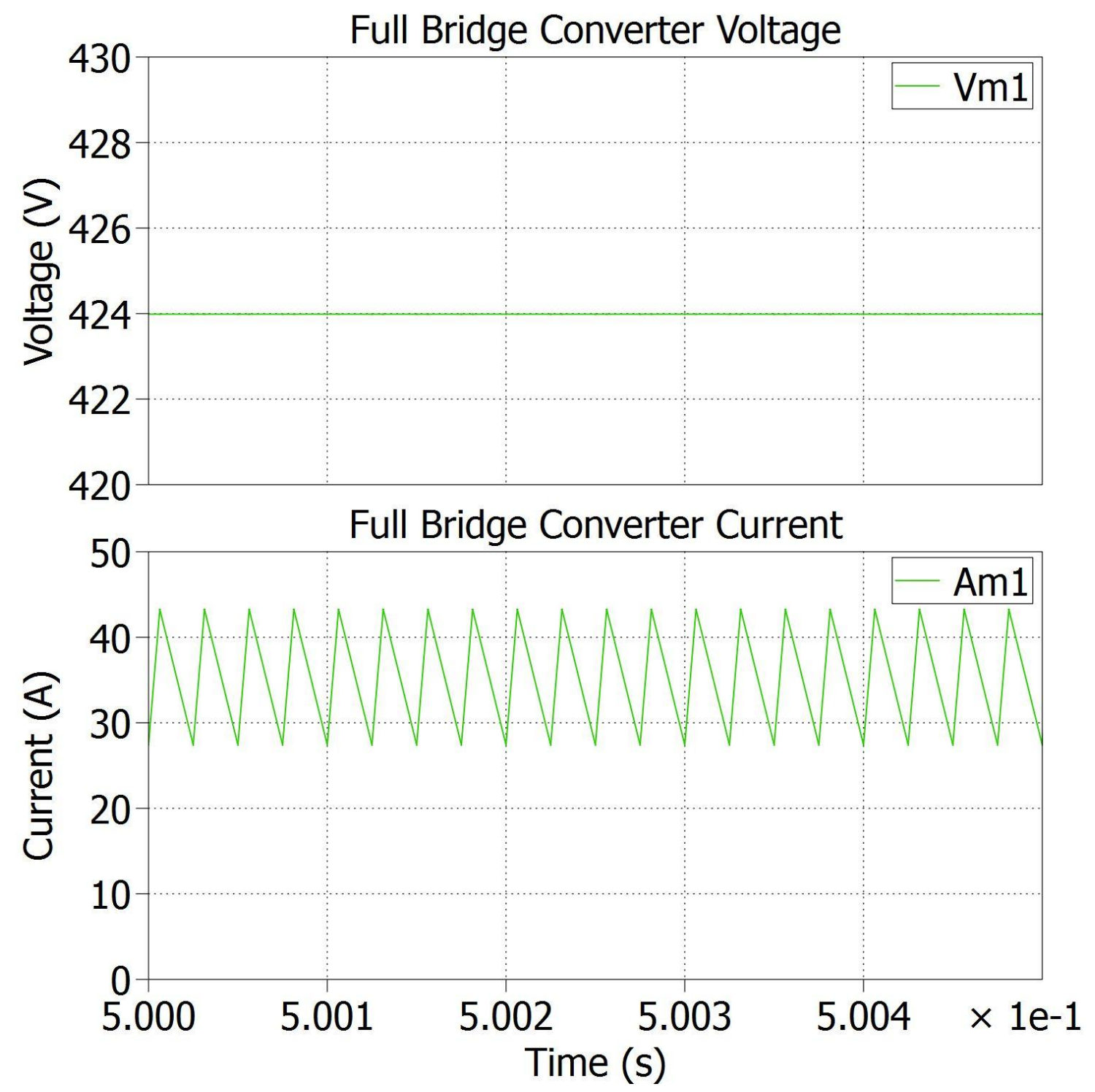

Figure 3.17: Full Bridge Converter PLECSim Simulation Results

As the simulation waveform shows, the designed circuit operates well within the desired parameters, achieving a value of approximately $424 \mathrm{~V}$ and with a very low output voltage ripple. The inductor current shows that this converter always operates in the continuous current mode keeping the inductor current always greater than zero. 


\subsubsection{Component Selection}

This stage's switching requirements could be fulfilled by several different types of devices. A device is needed that can block a voltage of $240 \mathrm{~V}$, allows a passing current of $41.88 \mathrm{~A}$, and can switch at $20 \mathrm{kHz}$. As with the inverter stage, an IGBT is used as the switching device in the Full Bridge Converter. This transistor style will keep conduction losses low while switching at the low frequency of this stage and can easily be designed to block the appropriate voltages at the desired passing current. The specific part chosen is the International Rectifier IRG7PH42UD1PbF. This transistor has a blocking voltage of $1200 \mathrm{~V}$ with a maximum pulse current allowance of $200 \mathrm{~A}$, both within operating conditions for this stage. This device has a $\mathrm{V}_{\text {ce(on) }}$ of $1.7 \mathrm{~V}$. A soft switching style IGBT was chosen for this stage as well to keep switching losses low. This device would have a gate voltage of approximately $8 \mathrm{~V}$, based on the $150{ }^{\circ} \mathrm{C}$ measurement in Figure 3.18. A custom transformer with the appropriate turn's ratio would need to be ordered if this design was to be implemented as well as a custom inductor to allow for a high inductance of $500 \mathrm{uH}$ with a large current requirement of $41.88 \mathrm{~A}$. Finally, a diode design must be selected that can handle the current and voltage requirements of this stage. The Vishay $400 \mathrm{U}(\mathrm{R})$ Standard Recovery Diode has a maximum reverse voltage of $800 \mathrm{~V}$ and a maximum forward current of $400 \mathrm{~A}$. These specifications fall within the simulated values with a comfortable safety margin. After component for this stage are selected, a power loss and thermal analysis is the next step. 


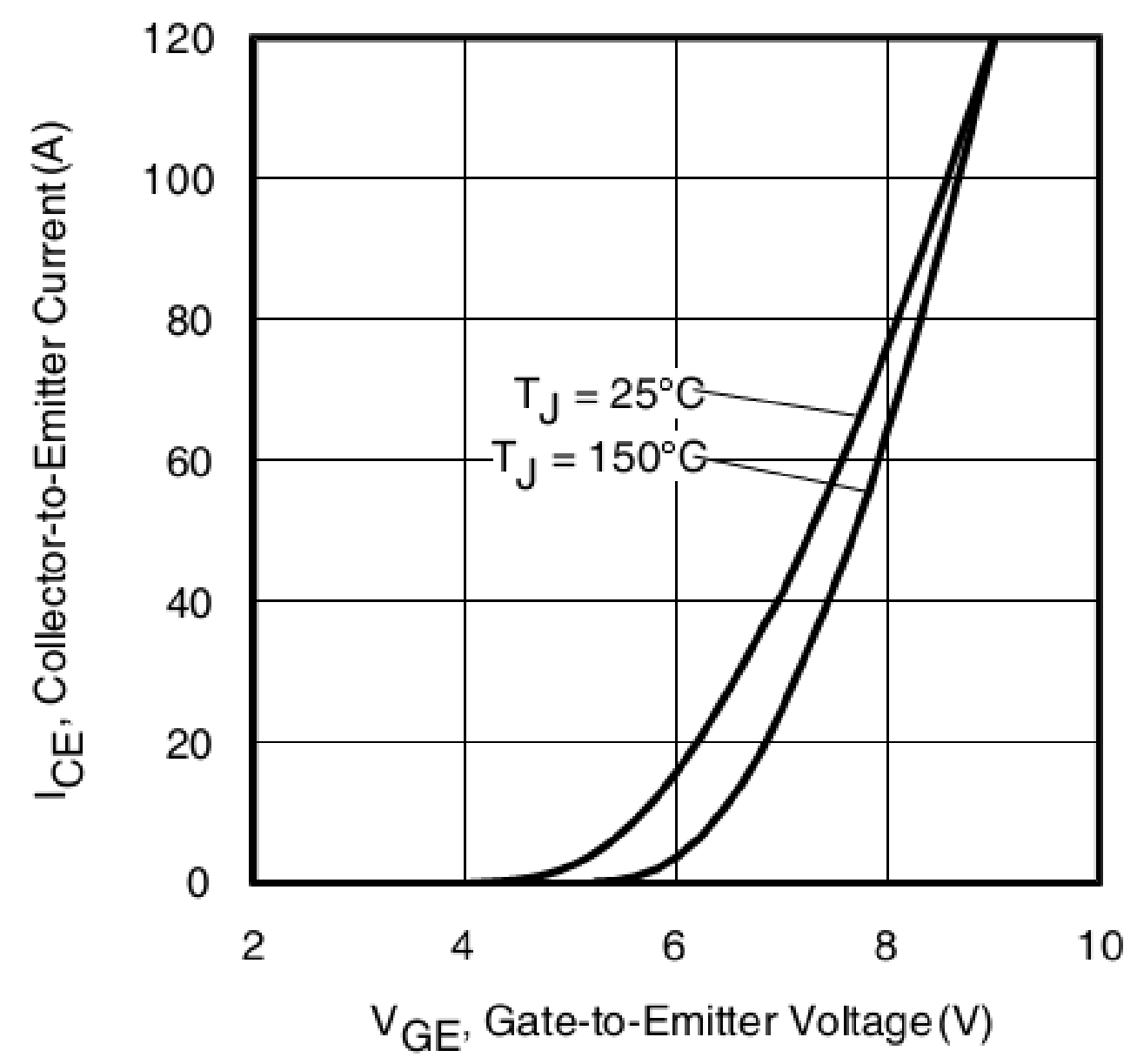

Figure 3.18: Full Bridge Converter IGBT Gate Voltage Transfer Characteristic

\subsubsection{Power and Thermal Analysis}

Similar to the Inverter stage, the major power lost in the Full Bridge Converter is due to the IGBTs. However, the power lost in this stage due only to the conduction and turn off switching. Since a soft switching style IGBT is used, there is no combined turn on time and it is not included in the calculation of losses. Using a similar method as with the inverter stage conduction losses are calculated to $11.74 \mathrm{~W}$ using Equation 3.5 [7]. With a combined turn off time of 460 nsec, switching losses are calculated at $37.68 \mathrm{~W}$ using Equation 3.6. 
Combining these values together gives combined losses for the inverter stage at $49.42 \mathrm{~W}$. Just as with the inverter, using two gates allows the dissipated power to be at a more manageable level. For this stage, the power dissipated for each IGBT is $24.71 \mathrm{~W}$. With this modification and Equation 3.7, a thermal resistance for the heat sink is determined to be $R_{\theta, S A}$ of $3.81{ }^{\circ} \mathrm{C} / W$ at $150^{\circ} \mathrm{C}$ [7]. The $6400 \mathrm{BG}$ heat sink from Aavid Thermalloy provides $R_{\theta, S A}$ of $2.7^{\circ} \mathrm{C} / W$ and will match the IR IGBT transistors used in this stage also. Using this heat sink will give an actual junction temperature of $122.5{ }^{\circ} \mathrm{C}$, within the operating conditions for the selected IGBTs.

Combining the Full Bridge Converter and H-Bridge Inverter designs, the source of the system, the Prius battery pack, matches the requirements discerned at the onset of the research for the load of a $240 \mathrm{~V}_{\mathrm{rms}} 60 \mathrm{~Hz}$ single phase signal. The next steps are to specify and design the support system for these two interfaces. This includes creating a low bus voltage line, controlling the signals to each interface's switches, and driving the transistors used in the design.

\subsection{Forward Converter}

This V2G interface is designed to stand alone on only the power it receives from the Prius' system itself. Therefore, a low voltage line is needed in order to provide power for a controller, gate drivers, and any other low voltage components needed. For this design, $8 \mathrm{~V}$ is selected as the low voltage line's value due to that being the maximum low voltage required from the Full Bridge 
Converter gate driving voltage. To fulfill this need, the Forward Converter PEI is used. A Forward Converter is a DC/DC converter that uses a transformer to decrease the output voltage and is very useful for designs with large voltage decreases, since a non-transformer design such as a Buck Converter would require an extremely low duty cycle resulting in a largely inefficient design [3]. On the secondary winding side of the transformer is a filter much like is on other DC/DC converters. The schematic for a Forward Converter is shown in Figure 3.19.
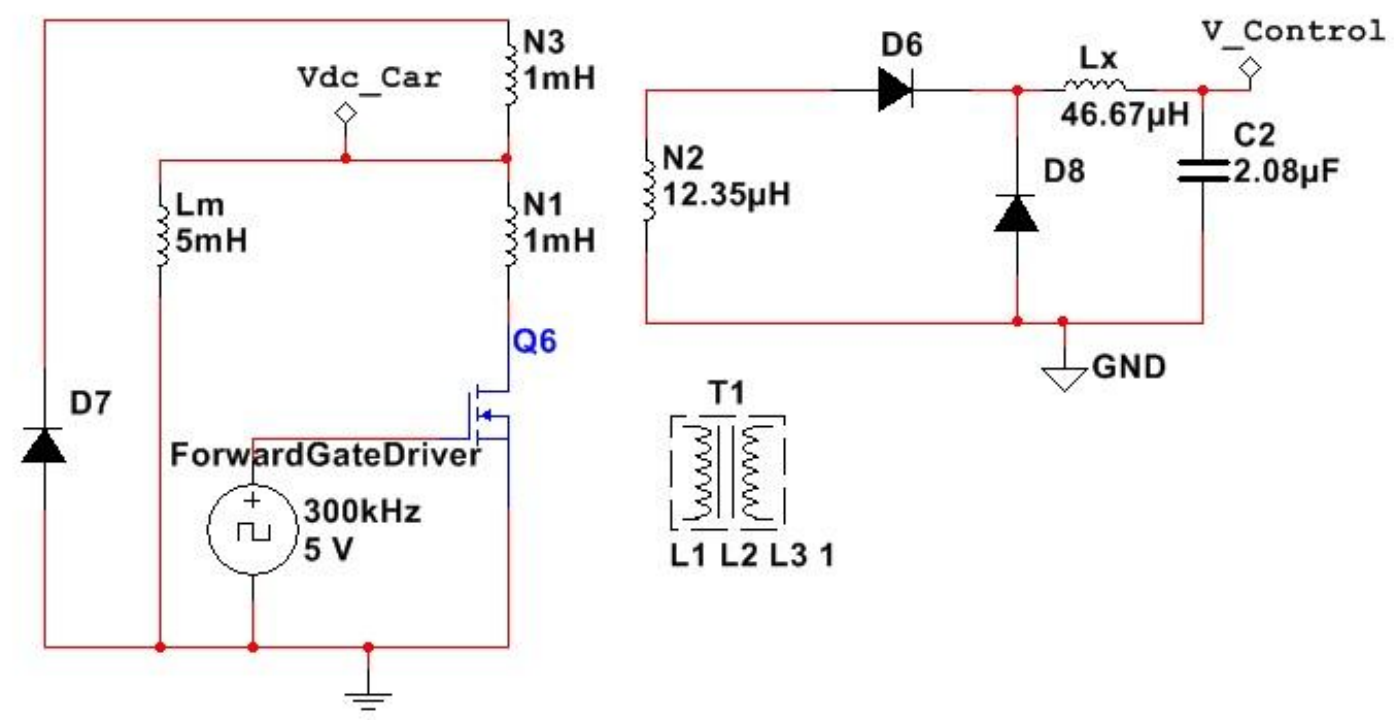

L1 L2 L3 1

Figure 3.19: Forward Converter Schematic

This device receives its input from the connections on the retrofitted PHEV Prius battery pack, which for this research design is a constant 240 Vdc. Since this low voltage bus is for driving smaller devices, a low average inductor current is set at $1 \mathrm{~A}$. The output ripple voltage is kept at $1 \%$ for this stage. 


\subsubsection{Forward Converter Design}

For the design of the Forward converter, first the duty cycle and switching frequency are chosen to be $30 \%$ and $300 \mathrm{kHz}$ respectively. Using these selected values, the windings ratio on the transformer between primary and secondary windings is determined to be 9 using Equation 3.13. The windings

$$
\frac{N_{1}}{N_{2}}=\frac{V_{S} D}{V_{O}}
$$

ratio between primary and auxiliary windings is set to 1 , in accordance with common convention in design of Forward Converters. The output inductance to guarantee continuous current is found using Equation 3.14 to be $46.67 \mathrm{uH}$ while the minimum output capacitance is found using Equation 3.15 to be $2.08 \mathrm{uF}$.

$$
\begin{aligned}
& L_{x}=\frac{V_{O}(1-D)}{0.4 I_{O} f} \\
& C=\frac{1-D}{8 L_{x} \frac{d V_{O}}{V_{O}} f^{2}}
\end{aligned}
$$

\subsubsection{Forward Converter Simulation}

The forward converter simulation is run using National Instrument's MultiSim software package. The results of the simulation are shown in Figure 3.20. 


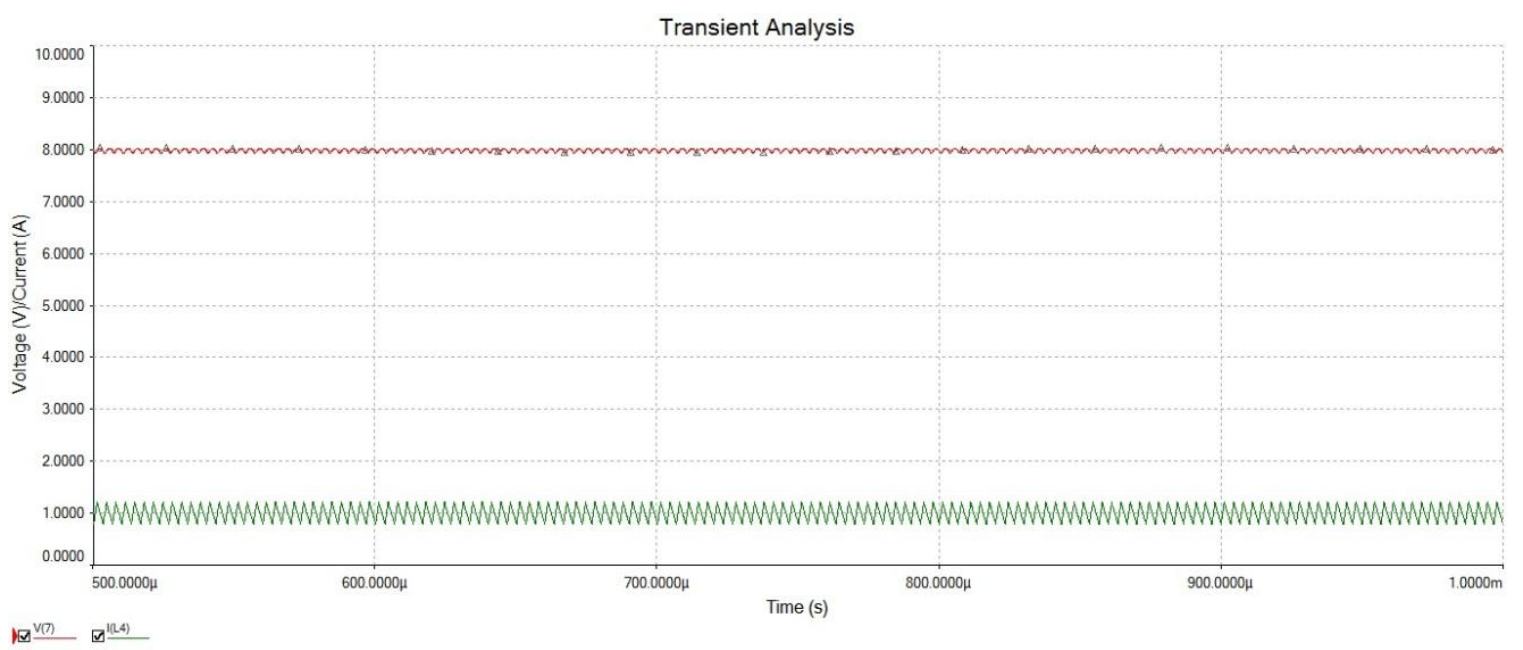

Figure 3.20: Forward Converter MultiSim Simulation

As can be seen in the simulation, the voltage stays near the target voltage of $8 \mathrm{~V}$. In addition, the inductor current stays positive assuring that the converter always operates in the continuous current mode near $1 \mathrm{~A}$ inductor current specified for this stage. As with the Full Bridge Converter, it is important for the stable operation of this PEI that the design operates in the continuous current mode.

\subsubsection{Component Selection}

This stage has several requirements that set it apart from the other stages of the design. This stage has a lower voltage and current requirement of $240 \mathrm{~V}$ and approximately $1 \mathrm{~A}$ respectively. In addition, the switching frequency for this stage is at $300 \mathrm{kHz}$, much higher than other stages. IGBTs are capable of being driven at this speed, but when they are the, switching losses are relatively high when compared to other device types. For this power electronic interface, MOSFETs are the better choice for switch operations due to the low blocking 
requirements and much higher switching frequency. A MOSFET provides better switching losses at higher frequencies than IGBTs are capable of. An appropriate MOSFET selected is the Infineon IPW65R037C6 650V CoolMOS C6 Power Transistor. This transistor has a maximum $\mathrm{V}_{\mathrm{DS}}$ of $700 \mathrm{~V}$ and a maximum pulse $I_{D}$ of 297 A which are both well within the tolerances for this stage. Though this MOSFET has no listed absolute maximum for switching frequency, $300 \mathrm{kHz}$ is a very common switching frequency for this transistor to handle. Because of the low current requirement of this stage, a gate voltage of $4.5 \mathrm{~V}$ is used. This value is determined using Figure 3.21. As in the full bridge converter, a custom transformer will need to be ordered to match the specifics of this design.

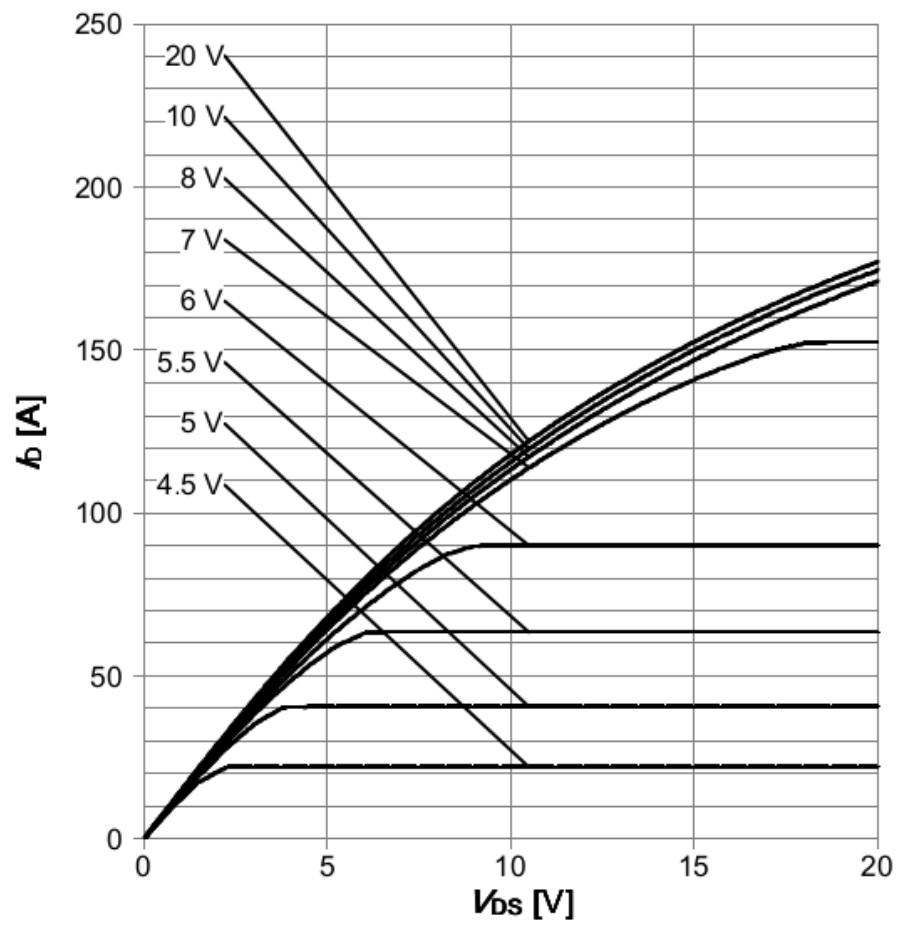

Figure 3.21: Forward Converter MOSFET Gate Voltage Transfer Characteristic 


\subsubsection{Power and Thermal Analysis}

Major power losses in this stage come from the conduction and switching losses in the MOSFET. While switching losses are determined by again using Equation 3.6, conduction losses are calculated using Equation 3.16 [7]. $I_{\text {Drms }}$ is taken from the RMS value of the output current and is determined to be $0.71 \mathrm{~A}$.

$$
P_{C}=R_{D S(o n)} I_{D r m s}^{2} D
$$

The selected MOSFET has a drain-source on-state resistance $\left(R_{D S(o n)}\right)$ of $0.04 \Omega$ which leaves conduction losses of $0.01 \mathrm{~W}$.

This MOSFET has a combined turn on time of 24 nsec while having a turn off time of 147 nsec. Switching losses are calculated for the MOSFET to be 7.24 W leading to combined losses for the MOSFET in the forward converter to be $7.25 \mathrm{~W}$. Using Equation 3.7, the maximum $R_{\theta, S A}$ for this switch is $14.86^{\circ} \mathrm{C} / \mathrm{W}$ [7]. The Aavid Thermalloy 530801B05150G heat sink in Figure 3.22 has a $R_{\theta, S A}$ of $6.3^{\circ} \mathrm{C} / W$ which is well below the maximum value. This design has a calculated junction temperature of $101^{\circ} \mathrm{C}$.

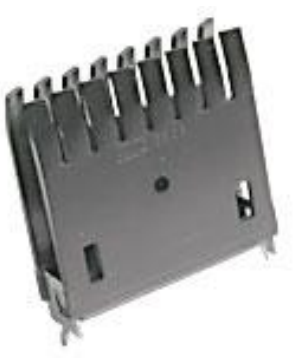

Figure 3.22: Aavid Thermalloy 530801B05150G Heat Sink 
This design represents the last PEI involved in this V2G interface. Its objective to create a low bus voltage is set out and completed within specification. The next step is to decide on the component that will control the switching signals for the PEls and also the component that will handle driving the transistors used in this design.

\subsection{Drive Support Systems}

In order for the previous components to function as designed, several support systems need to be included. These devices are chiefly concerned with controlling and driving the various switches involved with the entire system.

\subsubsection{Gate Driver Circuit}

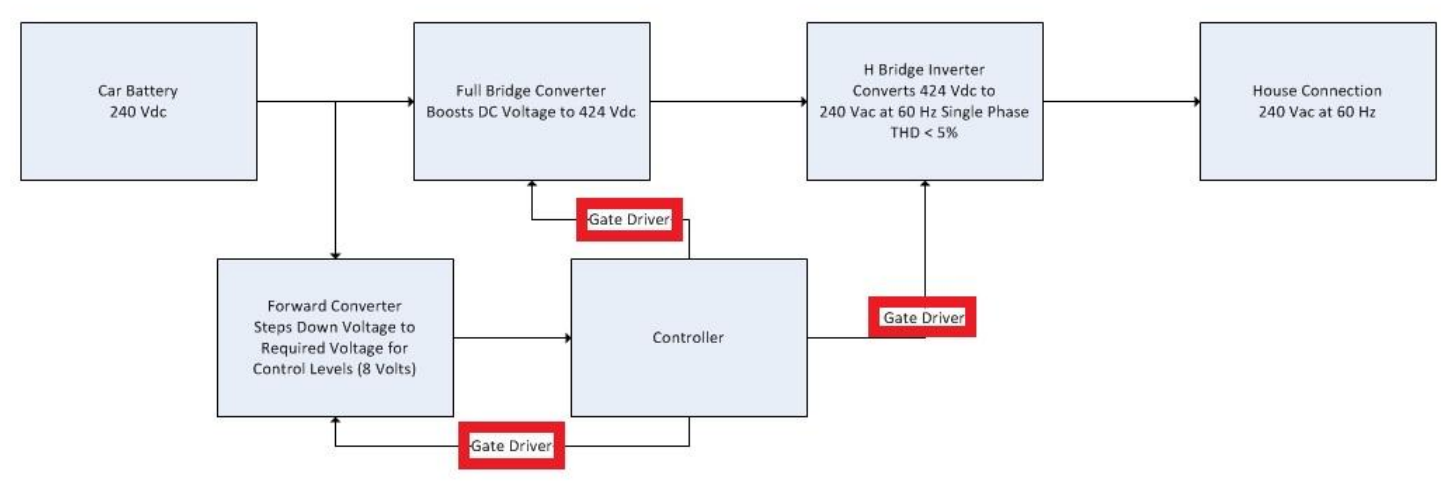

Figure 3.23: Location of Gate Drivers in Design

The gate driver IC for this thesis work has to be capable of driving each transistor at the correct voltage for either MOSFETs or IGBTs. It also needs to be capable of dual gate driving for the Full Bridge Converter and $\mathrm{H}$-Bridge Inverter stages. The gate driver chosen for this design is the Infineon 
2ED020I12-F2 Dual IGBT Driver IC. It is designed for a driving voltage of up to $20 \mathrm{~V}$, which is greater than any required driving voltage, and functions for both single and linked transistor pairs. In addition, it has functionality for MOSFETs and IGBTs, allowing it to function on all stages of this design.

This Gate Driver requires 2 signals sent from the controller in order to operate a single PWM pair of IGBTs. This means a total of 4 PWM signals are needed from the controller to manage both the $\mathrm{H}$-Bridge Inverter and Full Bridge Converter. This gate driver will send a set of signals to the "high and low" switch pairs individually. In effect, 2 gate drivers will be needed for each of these stages. The Forward Converter will only need a single gate driver IC and will not require a PWM signal from the controller. With these requirements set, an appropriate controller can be specified.

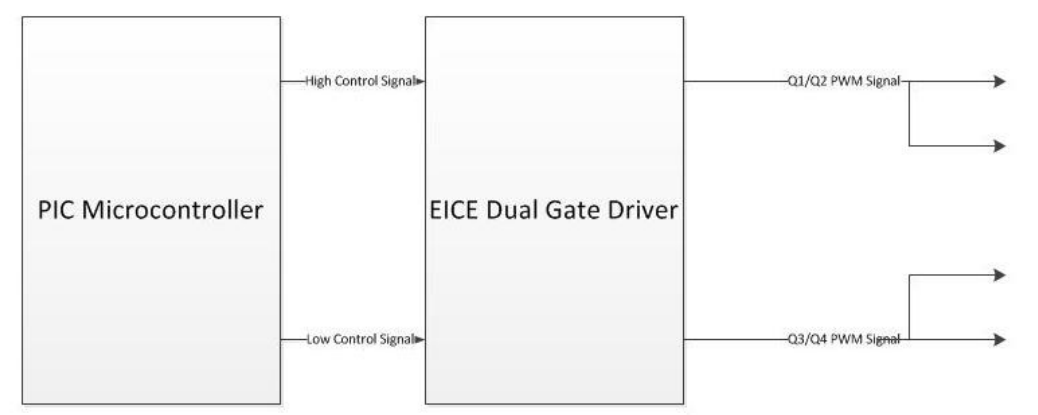

Figure 3.24: Gate Driver Block Diagram 


\subsubsection{Micro-Controller}

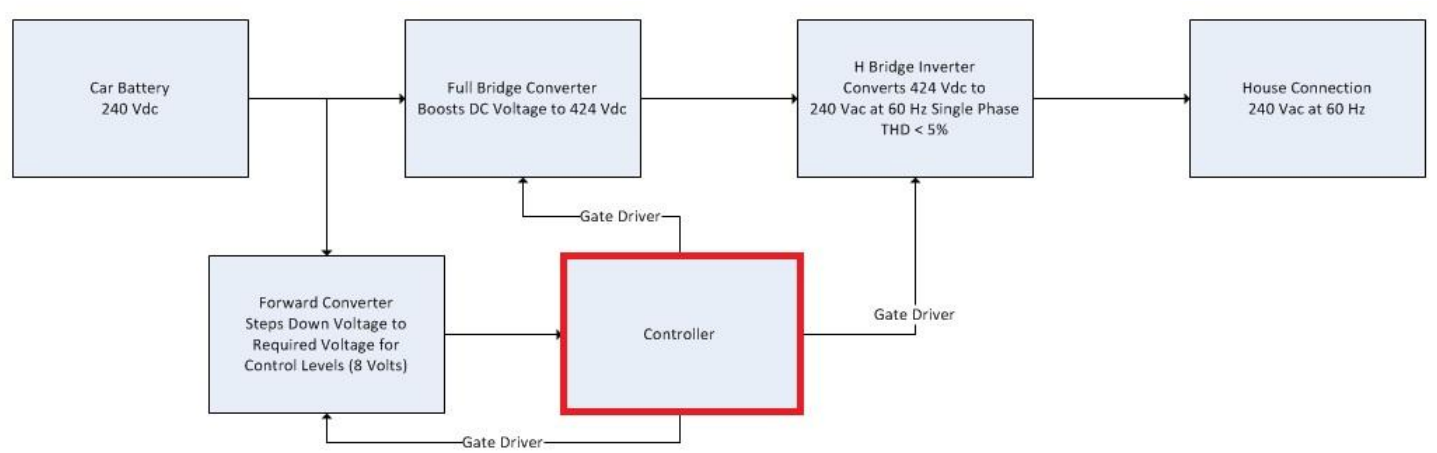

Figure 3.25: Location of Micro-Controller in Design

The micro-controller for this design has to be capable of managing several different signals at the same time. The controller chosen is the DSPIC33FJ16GS504-H/TL from PIC Microchip. This controller requires a $3.3 V_{d c}$ source to function which can be provided via regulator from the low voltage bus. It has the support for up to 4 PWM pairs each with independent timing as was specified in the previous section. It can also run its own comparators on board if needed for the inverter stage's PWM output. In addition, a simple digital output can manage the signal needed to drive the Forward Converter switching cycle. This microcontroller is able to handle the situations posed by this design and also has room for any additional modifications if needed. 


\section{CHAPTER 4}

\section{RESULTS AND CONCLUSIONS}

The objective of this thesis is the design of a V2G interface that converts the 240 Vdc energy of the 2007 Toyota Prius Retrofitted PHEV into $15 \mathrm{~kW}$ of 240 V $60 \mathrm{~Hz}$ single phase electricity that can be used to power a household. While this idea has been presented as a potential benefit of V2G technology, a literature search revealed no detailed analysis or design of such an interface. The design proposed by this research meets all requirements set out with no shortcomings. This design meets all specifications as defined in IEEE 1547 standard for additional harmonics entering a household network. This thesis shows the feasibility of such an endeavor.

This design provides many advantages over other styles that may be attempted. One such advantage is in the use of transformer isolated PEls. With the large steps up and down in voltage that must be taken at certain stages, a transformer design allows a larger change in voltage level without taxing switches too greatly. A non-transformer design would require much higher switching frequencies (resulting in greater switching losses) or operating the switch almost entirely in either the cut-off or saturation modes (an inefficient 
operating style). This design also minimizes power losses whenever possible. A major point in the design work has been to ensure that the power dissipated in each stage is an amount that is realistic and could be absorbed by a heat sink if this design were implemented.

In conclusion, this design implements a concept that has often been spoken of as a potential benefit of V2G technology. Through simulation and component searching, it is shown that a working model of this interface can theoretically be constructed. This idea adds a new benefit to consumers for owning a V2G capable vehicle and can further increase the popularity of EVs on the market. 


\section{CHAPTER 5}

\section{FUTURE STEPS}

After the completion of this research work, there are several items that must be considered for any future work. Primarily one must deal with the potential for voltage level variance based on the state of charge in the Prius' battery pack. The design described in this thesis treated the voltage level as a constant 240 Vdc source when in actuality there is the potential for the voltage level to swing between 210-270 Vdc based on the design of the battery depending on its state of charge. Due to such variances, a closed-loop feedback controller for the Full Bridge Converter should be implemented to ensure that the H-Bridge Inverter always receives the appropriate voltage input.

It is important to note that this research represents a first-stage design, mainly proving the feasibility and design of an interface to meet the initial specifications and goals. The next stage would need to involve reduction of costs in the device, mainly in components, while maintaining a minimum 
efficiency of the design. One such example is the need for several custom parts in this design that could prove to be more costly than desired. In addition, this design uses several instances of combined transistors in order to make heat dissipation more manageable. Minor adjustments to the design parameters could remove this additional cost. 


\section{REFERENCES}

[1] Damiano, A.; Gatto, G.; Marongiu, I.; Serpi, A.; A vehicle to grid planning tool for weakly interconnected power systems. Environment and Electrical Engineering (EEEIC), 2011 10th International Conference on , vol., no., pp.1-4, 8-11 May 2011

[2] Ehsani, M.; Gao, Y.; Gay, S; Emadi, A.; Modern Electric, Hybrid Electric, and Fuel Cell Vehicles. CRC Press

[3] Hart, Daniel W. 2011. Power Electronics. McGraw-Hill

[4] IEEE Std. 1547. IEEE Standard for Interconnecting Distributed Resources with Electrical Power Systems

[5] Kempton, W.; J. Tomić. 2005. Vehicle to Grid Implementation: from stabilizing the grid to supporting large-scale renewable energy. J. Power Sources Volume 144, Issue 1, 1 June 2005, Pages 280-294

[6] Letendre, S.; Kempton, W.; 2002. The V2G Concept: A New Model for Power? Public Utilities Fortnightly 140(4): 16-26

[7] Mohan, N.; Undeland, T. M.; Robbins, W. P.; Power Electronics: Converters, Applications, and Design. New York: John Wiley \& Sons, Inc., 1989.

[8] Sikai Huang; Infield, D.; The potential of domestic electric vehicles to contribute to Power System Operation through vehicle to grid technology. Universities Power Engineering Conference (UPEC), 2009 Proceedings of the 44th International , vol., no., pp.1-5, 1-4 Sept. 2009

[9] Yiyun, T.; Can, L.; Lin, C.; Lin, L.; Research on Vehicle-to-Grid Technology. Computer Distributed Control and Intelligent Environmental Monitoring (CDCIEM), 2011 International Conference on, vol., no., pp.10131016, 19-20 Feb. 2011

[10] http://www.kohlerpower.com/residential/solutions/sizingcalculator.htm?sectio nNumber $=13561$ \&nodeNumber $=1$ \&contentNumber=103\#advanced_result_calc_ outer_12

[11] http://www.gillettegenerators.com/cgi-bin/sizing.cgi

[12] http://www.electronics-tutorials.ws/transistor/tran_4.html 
[13] http://electronicdesign.com/article/power/semiconductor_conference_stresse s_the_importance_of_power_in_future_technology 


\section{CURRICULUM VITAE}

NAME: $\quad$ Michael Kevin Schoen

ADDRESS: 1120 Larchmont Avenue

Louisville, KY 40215

DOB: $\quad$ Dayton, Ohio - March 8, 1988

EDUCATION

\& TRAINING: BS ECE, University of Louisville, 2011

PROFESSIONAL SOCIETIES: IEEE Student Branch, IEEE Student Member, AIAA Student Member 